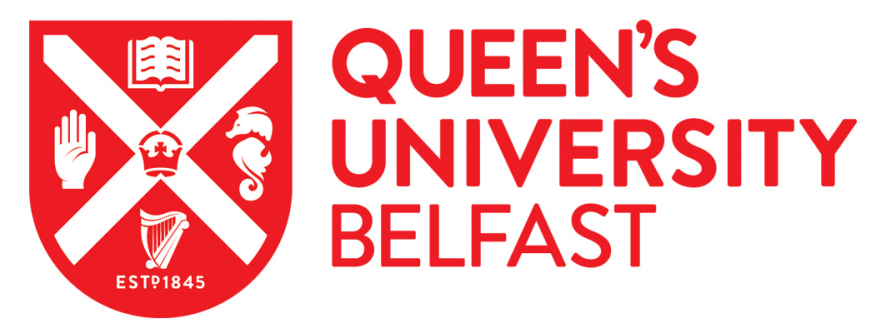

\title{
The role of material characterisation in the crush modelling of thermoplastic composite structures
}

Tan, W., Falzon, B. G., Price, M., \& Liu, H. (2016). The role of material characterisation in the crush modelling of thermoplastic composite structures. Composite Structures, 153, 914-927.

https://doi.org/doi:10.1016/j.compstruct.2016.07.011

\section{Published in:}

Composite Structures

\section{Document Version:}

Peer reviewed version

\section{Queen's University Belfast - Research Portal:}

Link to publication record in Queen's University Belfast Research Portal

\section{Publisher rights}

(C) 2016 Elsevier Ltd.

This manuscript version is made available under the CC-BY-NC-ND 4.0 license http://creativecommons.org/licenses/by-nc-nd/4.0/,which permits distribution and reproduction for non-commercial purposes, provided the author and source are cited.

\section{General rights}

Copyright for the publications made accessible via the Queen's University Belfast Research Portal is retained by the author(s) and / or other copyright owners and it is a condition of accessing these publications that users recognise and abide by the legal requirements associated with these rights.

Take down policy

The Research Portal is Queen's institutional repository that provides access to Queen's research output. Every effort has been made to ensure that content in the Research Portal does not infringe any person's rights, or applicable UK laws. If you discover content in the Research Portal that you believe breaches copyright or violates any law, please contact openaccess@qub.ac.uk. 


\section{Accepted Manuscript}

The role of material characterisation in the crush modelling of thermoplastic composite structures

Wei Tan, Brian G. Falzon, Mark Price, Haibao Liu

PII:

$$
\text { S0263-8223(16)30725-5 }
$$

DOI: http://dx.doi.org/10.1016/j.compstruct.2016.07.011

Reference: COST 7611

To appear in:

\section{Composite Structures}

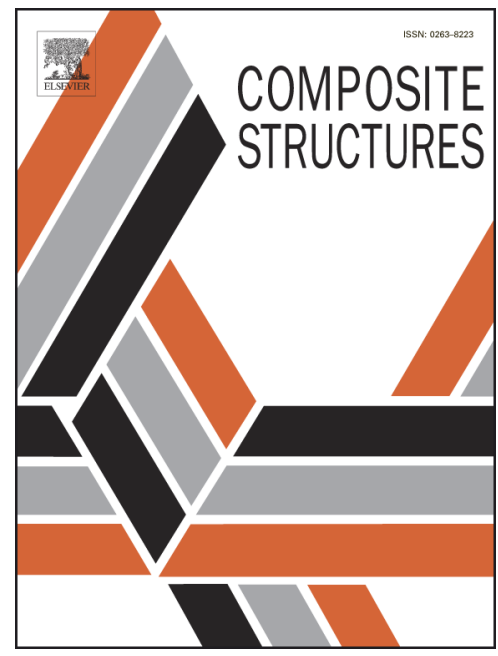

Received Date: $\quad 26$ May 2016

Accepted Date: $\quad 6$ July 2016

Please cite this article as: Tan, W., Falzon, B.G., Price, M., Liu, H., The role of material characterisation in the crush modelling of thermoplastic composite structures, Composite Structures (2016), doi: http://dx.doi.org/10.1016/ j.compstruct.2016.07.011

This is a PDF file of an unedited manuscript that has been accepted for publication. As a service to our customers we are providing this early version of the manuscript. The manuscript will undergo copyediting, typesetting, and review of the resulting proof before it is published in its final form. Please note that during the production process errors may be discovered which could affect the content, and all legal disclaimers that apply to the journal pertain. 


\title{
The role of material characterisation in the crush modelling of thermoplastic composite structures
}

\author{
Wei Tan 1,2, Brian G. Falzon 2*, Mark Price ${ }^{2}$, Haibao Liu ${ }^{2}$ \\ ${ }^{1}$ School of Mechanical and Electrical engineering, Central South University, Changsha 410083, China \\ 2School of Mechanical and Aerospace Engineering, Queen's University Belfast, Ashby Building, Belfast, \\ BT9 5AH, UK
}

* Corresponding author: b.falzon@qub.ac.uk (B.G. Falzon)

Tel: +44 (0)2890975640

\section{Abstract}

The predictive capability of high fidelity finite element modelling, to accurately capture damage and crush behaviour of composite structures, relies on the acquisition of accurate material properties, some of which have necessitated the development of novel approaches. This paper details the measurement of interlaminar and intralaminar fracture toughness, the non-linear shear behaviour of carbon fibre (AS4)/thermoplastic Polyetherketoneketone (PEKK) composite laminates and the utilisation of these properties for the accurate computational modelling of crush. Double-cantilever-beam (DCB), four-point end-notched flexure (4ENF) and Mixed-mode bending (MMB) test configurations were used to determine the initiation and propagation fracture toughness in mode I, mode II and mixed-mode loading, respectively. Compact Tension (CT) and Compact compression (CC) test samples were employed to determine the intralaminar longitudinal tensile and compressive fracture toughness. V-notched rail shear tests were used to measure the highly non-linear shear behaviour, associated with thermoplastic composites, and fracture toughness. Corresponding numerical models of these tests were developed for verification and yielded good correlation with the experimental response. This also confirmed the 
accuracy of the measured values which were then employed as input material parameters for modelling the crush behaviour of a corrugated test specimen.

Keywords: A. Polymer-matrix composites (PMCs); B. Delamination; B. Fracture toughness; C. Finite element analysis;

\section{Introduction}

Thermoplastic composite materials are showing great potential for adoption within the aircraft, automotive and railway industries. It is likely that more thermoplastic composite components will be used in the near future, in lieu of thermoset composites, to replace components which were previously manufactured from metals or thermoset composites. Thermoplastic resins offer a number of advantages over conventional thermosetting resins such as epoxies. Thermoplastics exhibit chemical and impact resistance; they may be used over a wide range of temperatures, and have an 'unlimited' shelf life [1]. Among many other high performance thermoplastic polymers like polyetheretherketone (PEEK), polyphenylene sulphide (PPS) and Polyethylenimine (PEI), semi-crystalline PEKK is one of the most promising polymers that can be used for structural applications because of its excellent environmental resistance and higher toughness. PEKK also has a lower processing temperature and is more economical than PEEK. It has higher mechanical properties than PPS and PEI, which makes PEKK a prospective candidate for use in fibre reinforced high performance applications. Although PEKK exhibits excellent properties, the fracture toughness database and behaviour under shear loading of this material is not available in the literature.

The fracture behaviour of composites can be quantified by measuring their toughness and it can be generally classified into interlaminar or intralaminar fracture. There are several existing standard test methods to characterise the interlaminar fracture toughness. For Mode I tests, the double-cantilever-beam (DCB) test is the most widely used approach and is the method 
adopted by the internationally-recognised standard, ASTM D5528-01 2002 [2]. While for Mode II, the ENF test is a recently announced test method (ASTM standard D7905/D7905M [3]) for the determination of Mode II interlaminar fracture toughness of unidirectional fibre-reinforced polymer matrix composites. However, the unstable crack growth issue exists for this common configuration and only initiation fracture toughness can be obtained. Some other researchers have made use of the four-point end-notched flexure (4ENF) [4] which can deliver a stable crack propagation to yield a resistance curve which is used to determine the propagation fracture toughness. For mixed mode fracture toughness, the Mixed Mode Bending (MMB) configuration is often used for the wide range of mode mixity it can create (ASTM D6671-01) [5]. Although existing test standards are able to measure the interlaminar fracture toughness, there still remains disagreement over the choice of initiation fracture toughness or propagation fracture toughness as an input material parameter to model the delamination behaviour [6].

Fibre-dominated failure is the main failure mode during longitudinal tension or compression and the energy consumed by these failure processes is much larger than for matrixdominated failure [7]. Particularly, fibre failure usually occurs as a result of fibre breakage/fibre pull-out under tension or crushing/kinking under compression. Experimental determination of the fracture toughness associated with these fibre failure modes is significant to accurately model the fibre-dominated damage behaviour. Compact Compression (CC) and Compact Tension (CT) tests described in ASTM E399 [8] and E1820 [9] originally designed for the testing of metallic materials, can be adapted for the determination of both tensile and compressive fibre-dominated fracture toughness $[7,10]$.

Transverse or shear loading may lead to large nonlinear deformation and subsequent matrix cracking, which can be defined as matrix-dominated failure [11, 12]. Composite materials may exhibit significant nonlinearity before failure, particularly with respect to shear deformations. This kind of failure was frequently observed in composite bolted joints manufactured using cross- 
ply and notched laminates [13, 14], as well as the formation of permanent indentations after impact events $[15,16]$. Therefore, a model dealing with shear non-linearities is required to accurately predict the failure under multiaxial loading states. The V-notched rail shear test method (ASTM standard D7078/D7078M-12) [17] is essentially a combination of the best features of two commonly used methods, the losipescu Shear [18] and the Two-Rail Shear test method [19], generating a relatively uniform shear stress state within a larger gauge section between the V-notches as well as eliminating edge crushing and the need of multiple loading holes.

While the potential superior energy absorbing capacity of carbon-fibre composite structures is repeatedly demonstrated in Formula One racing [9], the design of a cost-effective crashworthy carbon-fibre reinforced polymer (CFRP) automotive passenger cabin has yet to be realised. A major challenge in the development of land-based mass-transportation fibrereinforced polymer composite vehicles is ensuring a prescribed level of crashworthiness [27].The complex interacting failure modes, associated with carbon fibre composite material under crushing, present numerous challenges in predicting the crashworthiness of composite structures. A model that can capture the physical damage and deformation will be beneficial to the design and development of energy absorbing composite structures by providing a more detailed representation of the damage process.

In this study, a roadmap from material characterisation to crush modelling is presented, which builds on the work of the corresponding author's research group [15, 20-23]. A series of tests have been conducted for the measurement of interlaminar and intralaminar fracture toughness as well as the non-linear shear behaviour of AS4/PEKK composite laminates. A cohesive zone model [24] and an intralaminar damage model [15, 21, 23, 25-27] were implemented with the obtained fracture toughness values and non-linear behaviour to accurately predict the failure behaviour of composite test specimens under various loading conditions. 
Verification of the material parameters was carried out by simulating the material characterisation tests themselves. This confirmed the accuracy of the measured values which were then employed as material parameters for the computational modelling of the crushing behaviour of corrugated-shaped composite specimens. Excellent qualitative and quantitative correlation was achieved between the numerical models and experimental results. The fidelity of the computational models was able to provide detailed information on the evolution and propagation of splaying and fragmentation of the crushing composite, involving a complex interplay of fibre fracture, matrix cracking and delamination.

\section{Material and model}

\subsection{Specimen preparation}

The specimens used in this study were manufactured from unidirectional carbon fibre (AS4D 12K) / poly-ether-ketone-ketone (PEKK) tape provided by Cytec Engineered Materials ${ }^{\circledR}$ with a volume fraction of $60 \%$ [28]. Cross-ply AS4/PEKK composite plates were fabricated using a Collin ${ }^{\circledR}$ heated press.

Interlaminar fracture toughness specimens were prepared from $180 \mathrm{~mm} \times 180 \mathrm{~mm}$ unidirectional panels $\left(\left[0^{\circ}\right]_{24}\right)$. High temperature polyimide film (Kapton ${ }^{\circledR} 50 \mathrm{HN}$ with a thickness of $12.7 \mu \mathrm{m}$, coated with a release agent Freekote ${ }^{\circledR} 700 \mathrm{NC}$ on both surfaces) were implanted in the middle of the layup to create a starter crack of length $65 \mathrm{~mm}$ for DCB and 4ENF specimens, and 40mm for MMB specimens. Once the mould was prepared (as shown in Figure 1a, flat mould surface for coupon tests and corrugated mould surface for crushing tests), the prepreg laminate was wrapped along the longitudinal (fibre) direction with a high temperature polyimide film $\left(\right.$ Kapton $\left.^{\circledR}\right)$, which restrains the transverse flow of the resin out of the mould during the consolidation cycle and ensures a better surface finish of the final laminate. The wrapping keeps the two transverse sides of the laminate open and facilitated bleeding of any excess resin during 
consolidation. Intralaminar CC, CT specimens with a lay-up of $\left[90^{\circ} / 0^{\circ}\right]_{8 s}$ and shear test specimens with a lay-up of $\left[0^{\circ} 190^{\circ}\right]_{6 s}$ were similarly prepared.

The consolidation cycle involves three main steps (melting, consolidation and solidification) in accordance with the processing profile shown in Figure $1 \mathrm{~b}$. The composite laminated plates were heated at a constant rate of $15^{\circ} \mathrm{C} / \mathrm{min}$ to $372^{\circ} \mathrm{C}$ and held at this temperature for 30 minutes under 7 bar pressure. Afterwards, the composite plate was cooled to $120^{\circ} \mathrm{C}$ at $2^{\circ} \mathrm{C} / \mathrm{min}$ under the same pressure (7 bar) which was subsequently released and the composite plate cooled to room temperature in ambient conditions. After the consolidation cycle finished, the various interlaminar and intralaminar specimens were cut using a diamond coated circular saw blade.

\subsection{Typical failure modes}

Physically-based failure models are proposed for each failure mode in laminated fibre-reinforced composites with unidirectional plies at the ply level. The failure modes may be classified as intralaminar (matrix cracks and fibre pullout/breakage) and interlaminar (delamination) damage, as shown in Figure 2a. Fibre-dominated and matrix-dominated damage, which represent longitudinal (denoted by '11') and transverse damage behaviour (denoted by '22', '12' and '23') of a unidirectional lamina, are illustrated in Figure $2 b$.

\subsection{Brief overview of the computational composite damage model}

\subsubsection{Damage initiation}

A strain-based damage initiation function is used to model the material response in the longitudinal direction. The failure initiation criterion, based on Puck and Schürmann's [29] and Catalanotti et al. [30], was used for predicting matrix damage behaviour. A brief summary of fibredominated and matrix-dominated failure criteria are given below. Full details of the criteria may be found in $[15,20,21]$ and are not repeated here for brevity.

Fibre-dominated

$$
\varepsilon_{11}>0, F_{11}^{T}\left(\varepsilon_{11}\right)=\left(\frac{\varepsilon_{11}}{\varepsilon_{11}^{O T}}\right)^{2} \geq 1
$$




$$
\varepsilon_{11}<0, F_{11}^{C}\left(\varepsilon_{11}\right)=\left(\frac{\varepsilon_{11}}{\varepsilon_{11}^{O C}}\right)^{2} \geq 1
$$

$$
\begin{gathered}
\sigma_{N N} \leq 0, F(\theta)=\left(\frac{\sigma_{L N}}{S_{12}-\mu_{L N} \sigma_{N N}}\right)^{2}+\left(\frac{\sigma_{N T}}{S_{23}-\mu_{N T} \sigma_{N N}}\right)^{2} \\
\sigma_{N N}>0, F(\theta)=\left(\frac{\sigma_{N N}}{S_{23}}\right)^{2}+\left(\frac{\sigma_{L N}}{S_{12}}\right)^{2}+\left(\frac{\sigma_{N T}}{S_{23}}\right)^{2}+ \\
\lambda\left(\frac{\sigma_{N N}}{S_{23}}\right)\left(\frac{\sigma_{L N}}{S_{12}}\right)^{2}+\kappa\left(\frac{\sigma_{N N}}{S_{23}}\right)
\end{gathered}
$$

where the $F_{11}^{T}$ and $F_{11}^{C}$ are the failure indices for tensile and compressive loading, and the failure initiation strains ( $\varepsilon_{11}^{O T}$ and $\varepsilon_{11}^{O C}$ for tension and compression, respectively) are determined by the strengths in the respective directions, i.e. $\varepsilon_{11}^{O T}=X^{T} / E_{11}^{0}$ etc. The stress tensor $\sigma_{L N T}=$ $[T(\theta)] \sigma_{123}[T(\theta)]^{T}$ on the fracture plane was rotated using the standard transformation matrix $T(\theta)$, from the material coordinate system (123) to the fracture plane coordinate system (LNT), where $\theta$ is defined as the angle of the potential fracture plane. Parameters $\kappa$ and $\lambda$ are given by $\kappa=S_{23}^{2}-\left(Y_{T}\right)^{2} / S_{23} Y_{T}$, and $\lambda=2 \mu_{L N} S_{23} / S_{12}-\kappa$, where $S_{12}$ and $S_{23}$ are the shear strengths. The transverse friction coefficients $\mu_{N T}$ and $\mu_{L N}$, defined in [13], are based on Mohr-Coulomb theory where $\mu_{N T}=-1 / \tan \left(2 \theta_{f}\right), S_{23}=Y_{C} / 2 \tan \left(\theta_{f}\right)$ and $\mu_{L N}=$ $\mu_{N T} S_{12} / S_{23}, Y_{C}$ and $Y_{T}$ are the transverse compressive strength and transverse tensile strength, respectively. The fracture plane orientation, $\theta_{f}$, is typically found to be approximately $53^{\circ}$ for unidirectional composites [13] under uniaxial transverse compressive loading. For a general 3D load state, the orientation is not known a priori and is determined by the angle which maximizes the matrix dominated failure criteria functions. Brent's algorithm [31] was used for this purpose which combines a golden section search with parabolic interpolation.

\subsubsection{Damage evolution}

The damage tensor is a function of three monotonically increasing damage variables, bound by 0 (no damage) and 1 (complete failure), each one relating to a form of damage mode under a different loading state. $d_{11}^{T}$ refers to tensile damage in the fibre direction, $d_{11}^{C}$ refers to 
compressive damage in the fibre direction and $d_{\text {mat }}$ refers to matrix cracking due to a combination of transverse tension/compression and shear loading. The damage parameter associated with loading in the longitudinal direction is given by,

$$
d_{11}^{T(C)}\left(\varepsilon_{11}\right)=\frac{\varepsilon_{11}^{F T(C)}}{\varepsilon_{11}^{F T(C)}-\varepsilon_{11}^{O T(C)}}\left(1-\frac{\varepsilon_{11}^{O T(C)}}{\varepsilon_{11}^{T(C)}}\right)
$$

where the failure strains, $\varepsilon_{11}^{F T(C)}$, at which net-section fracture across the element occurs, is determined by the critical energy release rates $\Gamma_{11}^{T(C)}$, and longitudinal tensile/compressive strength, $X_{T(C)}$, given by,

$$
\varepsilon_{11}^{F T(C)}=2 \Gamma_{11}^{T(C)} / X_{T(C)} l_{f i b}
$$

where $l_{f i b}$ is the characteristic length. Mesh objectivity of the model was achieved by employing the crack-band model of Bažant and Oh [32]. The characteristic length associated with the longitudinal direction is determined by $l_{f i b}=V / A$, where $V$ is the element volume and $A$ is calculated using an approach proposed in [15].

The non-linear shear behaviour and damage propagation is shown in Figure 10. To quantify the modulus degradation during the strain hardening part and damage evolution in the strain softening part, two parameters are introduced to describe the damage propagation under transverse compression and shear loading: (1) shear damage in the strain hardening part, $d_{i j}^{I}$, and (2) shear damage in the strain softening part, $d_{i j}^{I I}$;

$$
\begin{gathered}
d_{m a t}=d_{i j}^{I}+d_{i j}^{I I}, \\
d_{i j}^{I}=1-G_{i j}^{*} / G_{i j}^{i n i}, \\
d_{i j}^{I I}=d_{i j}^{I}+\left(1-d_{i j}^{I}\right) \frac{\gamma_{i j}^{f}-\gamma_{i j, i n}^{o}}{\gamma_{i j}^{f}-\gamma_{i j}^{o}}\left(\frac{\gamma_{i j}-\gamma_{i j}^{o}}{\gamma_{i j}-\gamma_{i j, i n}^{o}}\right),
\end{gathered}
$$

where the final failure strain, $\gamma_{i j}^{f}$, is determined by $\gamma_{i j}^{f}=2 \mathrm{~g}_{i j} / \tau_{i j}^{o}+\gamma_{i j, i n}^{o}$ and $\mathrm{g}_{i j}=\Gamma_{i j} /$ $l_{\text {mat }} \cdot \gamma_{i j, i n}^{o}$ is the plastic strain at the onset of failure, $l_{\text {mat }}$ the characteristic crack length 
described in [15] and $\tau_{i j}^{o}$ is the shear strength. $\mathrm{g}_{i j}$ is the volume energy release rate associated with the elastic fracture energy and $\Gamma_{i j}$ is the shear fracture toughness. A quadratic interpolation function was used for the mixed-mode fracture energy [15].

\section{Interlaminar fracture toughness characterisation}

In this work, a double cantilever beam (DCB) configuration was used to determine the mode I fracture toughness while the four-point end-notched flexure (4ENF) configuration was used to determine mode II fracture toughness. Mixed-mode beam (MMB) tests were conducted to characterise the behaviour of the material under mixed-mode loading, as shown in Figure 3. Both the initiation and propagation fracture toughness of AS4/PEKK were obtained to set up the failure criteria based on the Benzeggagh-Kenane (B-K) law [33] to predict the mixed-mode damage propagation of AS4/PEKK structures.

The thickness and width of all the tested specimens were $3.36 \mathrm{~mm}$ and $20 \mathrm{~mm}$ respectively. The lengths, outer/inner span distances, initial delamination lengths and constant loading rates of these configurations are given by Table 1. Experiments with three different mode I/II mixities (25\%,50\%, 80\%) were carried out using the MMB apparatus with corresponding loading lever length, $c$, of $75.49 \mathrm{~mm}, 41.40 \mathrm{~mm}$ and $27.10 \mathrm{~mm}$. All the specimens were tested under displacement control, while the load displacement was recorded by the load cell.

\subsection{Data reduction}

A least squares plot was generated of the delamination length normalized by the specimen thickness, $a / h$, as a function of the cube root of compliance, $C^{1 / 3}$. Designating the slope of this line as $A_{1}$, the mode I interlaminar fracture toughness was calculated using modified compliance calibration (MCC) [2]:

$$
G_{I}=\frac{3 P^{2} C^{2 / 3}}{2 A_{1} b h}
$$


For mode II, four-point end-notched flexure (4ENF) [34] can achieve stable crack growth under displacement control. Hence it is possible to obtain a complete resistance curve (R-curve) to get the propagation fracture toughness. The relation between the applied load and the opening displacement was derived according to beam theory [35] and the mode II fracture toughness is given as follows,

$$
\begin{gathered}
\delta=\frac{P l^{2}(9 a+6 L-10 l)}{8 E_{1} B h^{3}} \\
G_{I I}=\frac{9 P^{2} l^{2}}{16 E_{1} B^{2} h^{3}}
\end{gathered}
$$

where $E_{1}$ is the longitudinal modulus, $B$ is the width, and $h$ is the half-thickness of the laminate. It is observed that according to corrected beam theory, $G_{I I}$ is independent of delamination length.

Mixed-mode interlaminar fracture toughness is calculated from the mode I and mode II components of the strain energy release rate [5],

$$
\begin{gathered}
G_{I}=\frac{3 P^{2}(3 c-L)^{2}}{4 b^{2} h^{3} L^{2} E_{1 f}}(a+\chi h)^{2} \\
G_{I I}=\frac{9 P^{2}(c+L)^{2}}{16 b^{2} h^{3} L^{2} E_{1 f}}(a+0.42 \chi h)^{2}
\end{gathered}
$$

where $P$ is applied load, $c$ the length of the loading lever, $2 L$ the span of the beam, $a$ is

delamination length, $\chi=1.18 \sqrt{E_{11} E_{22}} / G_{13}$, a crack length correction parameter, $E_{11}$ the longitudinal stiffness, $E_{22}$ the transverse stiffness, $G_{13}$ the shear modulus, and the bending modulus, $E_{1 f}$, is given in [5]. The total initial and propagation fracture toughness is determined by $G_{T C(R)}=G_{I C(R)}+G_{I I C(R)}$.

\subsection{Experimental and numerical results}

A resistance curve (R-curve) depicting $G_{I C}$, calculated by MCC as a function of delamination length, $a$, was generated to characterise the initiation and propagation fracture toughness for mode I DCB tests, shown in Figure 4. The average initiation fracture toughness was $G_{I C}=$ 
$0.924 \mathrm{~kJ} / \mathrm{m}^{2}$ with a coefficient of variation (CoV) of $8.1 \%$ and the propagation fracture toughness reached a plateau at $G_{I R}=1.564 \mathrm{~kJ} / \mathrm{m}^{2}$ with a CoV of $3.8 \%$.

Figure $4 \mathrm{~b}$ shows the mode II fracture toughness for all the 4ENF pre-cracked specimens. The average initiation fracture toughness was $2.358 \mathrm{~kJ} / \mathrm{m}^{2}$ with a CoV equal to $8.7 \%$. As the crack proceeds, the value of $G_{I I}$ in all cases remained nearly constant or with a slight positive gradient as the crack propagated. The average propagation fracture toughness was $2.113 \mathrm{k} J /$ $m^{2}$ with a CoV equal to $4.3 \%$.

The total fracture toughness of the various specimens obtained from the DCB, 4ENF and MMB tests are presented in Figure $4 \mathrm{c}$ as a function of the mode mix ratio. The mode interaction formulation suggested by Benzeggagh and Kenane (B-K law) [33] was used to fit the experimental data. Coefficients $\eta_{c}=2.129$ and $\eta_{R}=0.966$ show a good curve fit for both initiation fracture toughness and propagation fracture toughness respectively (Figure 4c).

Cohesive surface contacts were defined for the interface between plies to capture delamination using a bilinear traction-separation relationship [24, 36]. Element size in the interface was $0.5 \mathrm{~mm} \times 0.5 \mathrm{~mm} \times 0.25 \mathrm{~mm}$ (thickness). A penalty stiffness of $k=1 \times 10^{5} \mathrm{~N} / \mathrm{mm}^{3}$ was used. The nominal interfacial strength normal direction and in-plane shear directions were $\tau_{3}^{0}=61 \mathrm{MPa}$ and $\tau_{1(2)}^{0}=80.81 \mathrm{MPa}$ respectively. The validity of the cohesive zone model definitions and measured toughness values is demonstrated for different mode ratios by comparison with corresponding experimental results. Initiation and propagation fracture toughness values were assigned to the initial delamination interface region $\left(a_{1}=5 \mathrm{~mm}\right)$ and the crack propagation interface region $\left(a_{2}=20 \mathrm{~mm}\right)$ respectively. As shown in Figure $4 \mathrm{~d}$, the predicted load-displacement curves under different mode ratios achieved good correlation with experimental results. 


\section{Intralaminar fracture toughness}

Compact Tension (CT) and Compact Compression (CC) tests described in ASTM E399 [8] and E1820 [9] originally designed for the testing of metallic materials, were adapted for the determination of both tensile and compressive fibre-dominated fracture toughness [7, 10]. Five CT and four CC tests were carried out in a Hounsfield machine with a $50 \mathrm{kN}$ load cell, applying a quasi-static loading at a rate of $1 \mathrm{~mm} / \mathrm{min}$ and unloading at $5 \mathrm{~mm} / \mathrm{min}$. Multiple loading-unloading cycles were performed at different delamination lengths $(\Delta a-\mathrm{mm})$ in order to measure the fracture energy using the area method. All the dimensions of the CC and CT specimens are shown in Figure 8. A digital microscope was used to capture a magnified image of the crack-front. The Dantec $^{\circledR}$ digital image correlation (DIC) system was positioned to capture the strain field during the tests.

\subsection{Data reduction approaches}

\subsubsection{Area method}

The critical strain energy release rate can be calculated using the area method [37], where the overall energy consumed by crack growth of $\Delta a$, may be determined using

$$
\Gamma_{11}=\frac{1}{2 t \Delta a}\left(P_{1} d_{2}-P_{2} d_{1}\right)
$$

where the loads, $P_{i}$, and corresponding displacements, $d_{i}$, are defined in a representative load vs. displacement plot where $\left(d_{i}, P_{i}\right)$, are determined at some crack length $a_{i}$, and $\left(d_{i+1}, P_{i+1}\right)$ at crack length $a_{i+1}=a_{i}+\Delta a$.

\subsubsection{Compliance calibration method}

The compliance calibration method (CCM) [37] requires the elastic compliance of the specimen at each optically measured crack length, $a_{v i s}$, to be determined directly from the load displacement curve. The experimental $C$ vs. $a_{v i s}$ data for compact tension and compression was fitted with an exponential function, 


$$
C=\alpha \exp \left(\beta a_{v i s}\right),
$$

where $\alpha$ and $\beta$ were calculated to yield the best fit to the experimental data. The critical strain energy release rate can be calculated using the change in compliance, $C$, with critical load $P_{c}$, crack width $t$ and crack length $a$,

$$
\Gamma_{11}=\frac{P_{c}^{2}}{2 t} \frac{d C}{d a}=\frac{P_{c}^{2}}{2 t} \alpha \beta \exp \left(\beta a_{v i s}\right) .
$$

\subsubsection{Ply-level fracture toughness}

It was assumed that the laminate fracture toughness can be partitioned into the separate

contributions made by the $0^{\circ}$ plies and $90^{\circ}$ plies such that longitudinal tensile (compressive)

fracture toughness $\Gamma_{11}^{\mathrm{T}(\mathrm{C})}$ could be obtained from,

$$
\begin{gathered}
\Gamma_{11}^{\mathrm{T}}=2 \Gamma_{11}^{T(\text { lam })}-\Gamma_{22}^{\mathrm{T}} \approx 2 \Gamma_{11}^{T(\text { lam })} \\
\Gamma_{11}^{\mathrm{C}}=2 \Gamma_{11}^{C(\text { lam })}-\Gamma_{22}^{\mathrm{C}}
\end{gathered}
$$

$\Gamma_{11}^{T(l a m)}$ is the tensile laminate-level fracture toughness and $\Gamma_{22}^{\mathrm{T}}$ represents the fracture toughness associated with mode I transverse matrix tensile failure [7]. This value was found to be very similar to the interlaminar mode I fracture toughness [38]. $\Gamma_{11}^{C(\text { lam })}$ is the laminate-level fracture toughness associated with compressive loading, $\Gamma_{22}^{C}$ is the intralaminar fracture toughness of matrix under compression. Since the main failure mode of composite laminates under compressive and shear loading is very similar, $\Gamma_{22}^{C}$ was assumed to be the same as the intralaminar matrix toughness under shear loading, measured as $\Gamma_{22}^{C}=\Gamma_{12}=34.48 \mathrm{~kJ} / \mathrm{m}^{2}$ in section 5.1.

\subsection{Fractographic analysis}

Typical fracture surfaces of tested specimens were examined using Scanning Electron Microscopy (SEM) shown in Figure 5. The failure mode of the $90^{\circ}$ ply was mainly due to the transverse tensile matrix cracking leading to a clean fracture surface, while extensive tensile 
failure of fibre bundles was observed in the $0^{\circ}$ ply accompanied by fibre/matrix interface debonding and fibre pull-out.

For all CC specimens tested, the relative motion of the crack faces during shear failure induced bending ahead of the crack tip and subsequently a transition to fibre kinking failure occurred. An out-of-plane kink-band angle of $43.8^{\circ}$ is indicated in Figure $6 \mathrm{~b}$. The fractured fibres of a typical kind-band were observed in the SEM image (Figure 6c).

\subsection{Experimental and numerical results}

As indicated by the R-curves (Figure 7b and Figure 7d), the longitudinal tensile and compressive ply fracture toughness for AS4/PEKK is $\Gamma_{11}^{T}=243.9 \mathrm{~kJ} / \mathrm{m}^{2}$ with a CoV equal to $13.3 \%$ and $\Gamma_{11}^{\mathrm{C}}=108.3 \mathrm{~kJ} / \mathrm{m}^{2}$ with a CoV of $9.6 \%$ respectively. The average propagation fracture toughness was comparable to values obtained from the area method, confirming the consistency of these two data reduction methods. Multiple load-unload cycles (Figure 7a and Figure 7c) were performed to calculate the fracture toughness using the area method. Hysteresis loops were observed, as a result of inelastic behaviour and the unloading curves didn't return to the origin. This is most probably due to the occurrence of a certain amount of fibre pull-out and fibre/matrix debonding. The area of the surface enclosed within the hysteresis loop equals the amount of energy dissipated in fibre pull-out, fibre/matrix debonding and friction between fibre and matrix during the damage process.

An intralaminar finite element based damage model proposed in an accompanying paper [27], to capture the in-plane damage modes was used in the numerical modelling of the CT and CC specimens. Element size in the crack propagation section (area enclosed by the dashed red line in Figure 8) was $0.5 \mathrm{~mm} \times 0.5 \mathrm{~mm} \times 0.14 \mathrm{~mm}$ (thickness). The predicted CT results in Figure $7 \mathrm{c}$ and Figure 8a were in a good agreement with experiment observations. The damage contours reveal details of the failure modes involving matrix damage, fibre tensile splitting (initiating from the precrack tip) and compressive failure (far-end from the precrack tip) in the $0^{\circ}$ longitudinal direction. 
The numerical results for the $\mathrm{CC}$ specimen, shown in Figure 8b, capture the out-of-plane fibre kinking failure observed in the experimental test. Kink-band formation, initially matrixdominated failure, results from small misalignments of the fibres and subsequent matrix damage, fibre micro-buckling and fibre breakage in the composite laminates [39].

\section{Non-linear shear behaviour}

The V-notched rail shear test method (ASTM standard D7078/D7078M-12) [17] was used to measure the non-linear behaviour, shown in Figure 10a. Cross-ply $\left[0^{\circ} / 90^{\circ}\right]_{6 s}$ and unidirectional $\left[0^{\circ}\right]_{24}$ AS4/PEKK composite plates with 24 plies were fabricated using a Collin ${ }^{\circledR}$ heated press. The loading rates for both static and cyclic tests were $1 \mathrm{~mm} / \mathrm{min}$, while the unloading rate in cyclic tests was $5 \mathrm{~mm} / \mathrm{min}$. The applied load was measured continuously with a $50 \mathrm{kN}$ load cell. DIC was also used to measure the strain field under shear loading.

\subsection{Mode II intralaminar fracture toughness}

Figure 9 shows the behaviour of unidirectional laminate specimens loaded in shear, where the fibres are parallel to the load direction. These specimens failed with a crack propagating through the matrix in the central notch area with little plastic deformation. Fast fracture was triggered by the stress concentration at the notch tip, as expected. The mode II intralaminar matrix fracture toughness, obtained using the area method by dividing the total fracture energy by the central notch area yielded a value of $\Gamma_{12}=34.48 \pm 1.2 \mathrm{~kJ} / \mathrm{m}^{2}$.

\subsection{Material properties and model definition}

Considerable plastic shear strain and modulus degradation was observed with several consecutive loading-unloading cycles applied to test specimens shown in Figure 10c. Prior to damage initiation, shear loading and unloading occurs along gradients defined by the initial shear modulus, $G_{i j}^{i n i}$, and degraded shear modulus $G_{i j}^{*}$, respectively. According to plastic-damage theories, the plastic strain represents all irreversible deformations including those caused by matrix microcracks. The matrix behaviour, after yielding, can be approximated as perfectly plastic 
to allow the decomposition of the lamina nonlinear shear behaviour from the overall laminate shear response [20]. In this ply level model, the fibre rotation was not accounted for; an approach used in other models $[40,41]$. This non-linear behaviour was then fitted by an exponential model to capture the pseudo perfect-plastic behaviour of the matrix constituent.

$$
\tau_{i j}=\left\{\begin{array}{c}
\tau_{i j}^{Y}\left[\exp \left(\alpha \gamma_{i j}\right)-\exp \left(\beta \gamma_{i j}\right)\right], \quad \gamma_{i j} \geq 0 \\
\tau_{i j}^{Y}\left[-\exp \left(-\alpha \gamma_{i j}\right)+\exp \left(-\beta \gamma_{i j}\right)\right], \quad \gamma_{i j}<0
\end{array}\right.
$$

where $\tau_{i j}^{Y}$ is the initial yield strength, $\alpha$ and $\beta$ are the coefficients, determined by translating the shear chord modulus of elasticity line along the strain axis from the origin to $2 \%$ strain. To characterise the degradation of the shear modulus defined as the secant shear modulus for one loading-unloading cycle, a degraded shear modulus, $G_{i j}^{*}$, was introduced and fitted according to the strain-degraded modulus curve in Figure 10d. The degradation modulus was coupled with the plastic deformation in the constitutive relation, making it convenient to obtain the parameters through experiment results.

$$
G_{i j}^{*}=p_{1} \exp \left(p_{2}\left|\gamma_{i j}\right|\right)+p_{3} \exp \left(p_{4}\left|\gamma_{i j}\right|\right)
$$

The intralaminar damage model is detailed in [20]. A summary of all the material properties measured from interlaminar/intralaminar fracture toughness tests and nonlinear shear tests are given in Table 2.

\subsection{Experimental and numerical results}

Figure 10 e shows the load-displacement curves under static and cyclic loading. Monotonic and cyclic loading curves are coincident up to a displacement of approximately $6 \mathrm{~mm}$. Afterwards cyclic tests show a certain extent of damage recovery in the fracture process (displacement range from $10 \mathrm{~mm}$ to $15 \mathrm{~mm}$ ). The area under the load-displacement curve is the total energy dissipated in the overall process. The corresponding in-plane shear stress-strain curves, until final failure, are shown in Figure 10c. The cross-ply laminate shows initial elastic behaviour, giving a shear modulus of elasticity of $G_{12}=\Delta \tau / \Delta \gamma=5.02 \pm 0.2 G P a$. The offset in-plane 
shear strength was determined by translating the shear chord modulus of elasticity line along the strain axis from the origin by $2 \%$ and extending this line until it intersected the stress-strain curve, to give a shear strength of $S_{12}=80.81 \pm 1.5 \mathrm{MPa}$. The initial linear behaviour was followed by the onset of matrix plastic deformation (developed from $2 \%$ to $10 \%$ strain).

Several consecutive loading-unloading cycles were applied to specimens, and considerable permanent shear plastic strain was observed. This inelastic strain is irreversible due to the presence of plasticity and/or extensive matrix cracking. To characterise the stiffness degradation, the in-situ stiffness was defined as the secant shear modulus of each loadingunloading cycle as shown in the Figure 10c. The relationship between shear modulus and applied shear strain is plotted in Figure 10d. It can be seen that the shear modulus degraded quickly in the initial matrix yielding regime and then reached a constant level of $2.5 \mathrm{GPa}$ during the fibredominated load bearing process, confirming that the reduced stiffness is mainly associated with matrix plastic deformation.

The numerically predicted strain contours, at different loading stages, are compared with experimental results (Figure 10b) and show good qualitative and quantitative agreement. The predicted structural deformation and uniformly distributed fibre debonding on the surface of the $\mathrm{V}$ notched specimen were similar to those observed experimentally. The overall load-displacement response of the numerical test correlates well with experimental tests (Figure 10d) in the elastic region as well as the fibre rotation region and global fracture regime. The permanent deformation and degraded stiffness were well represented in the model when unloading was applied. The predicted peak load was shown to be in good agreement with the test response, indicating that the damage model, using data generated in this work, was able to accurately predict the onset fracture of cross-ply laminates accurately under shear loading. The damage propagation in the final stages, representing the energy dissipation, correlated well with experimental tests results. The good correlation achieved shows that it is feasible to use the decomposed non-linear shear 
behaviour, assuming perfectly-plastic properties for the matrix from the measured laminate, properties to predict the overall shear response.

\section{Crush modelling}

\subsection{Crushing test and finite element model}

Cross-ply [0/90]3s AS4/PEKK composite corrugated samples with 12 plies were fabricated with a Collinß heated press in a consolidation cycle as per the manufacturer's specifications. The specimens were tested in compression between two flat steel platens in a Hounsfield machine with a $50 \mathrm{kN}$ load cell. The force response was recorded directly from the load cell while the displacement was obtained from the moving crosshead. The crosshead speed was set at $5 \mathrm{~mm} / \mathrm{min}$, giving a nominal strain rate of $1 \times 10^{-3} / \mathrm{s}$. Virtual corrugated specimens were created in ABAQUS/Explicit 6.12, as shown in Figure 11. Material properties characterised in this paper were then used as input material parameters (summarized in Table 2) to model the crushing behaviour. The geometry was meshed using an approximate element size of $0.5 \mathrm{~mm}$ in the longitudinal (crush direction) and $1 \mathrm{~mm}$ in the transverse directions. In order for C3D8R elements to capture the bending behaviour, three elements through the thickness of each ply were used. To suppress spurious energy modes, an enhanced stiffness-based hourglass and distortion control were employed. The surface based cohesive behaviour was employed to capture delamination between adjacent plies. A general contact algorithm was utilised to generate a contact force between contact surfaces. 'Hard' contact conditions were defined between the platen and the plies as well as adjacent plies. The platen was modelled as an analytical rigid surface. The friction coefficients of ply-to-ply and ply-to-metal contact were set to 0.28 and 0.2 respectively, measured in [20]. The computational loading speed was fixed at $1 \mathrm{~m} / \mathrm{s}$ to reduce the CPU time whilst ensuring that the quality of the results was not affected by inertial effects. Selective mass scaling, which only scaled elements whose stable time increment was below $5 \mathrm{e}-08 \mathrm{~s}$, was also employed during the crushing process to achieve a reasonable run time. 
Low-pass filters were employed to remove the numerical oscillations as an artefact of explicit dynamic modelling. Models were run on a Windows Cluster with 16 CPUs with a run time of 32 hours.

An efficient strategy to delete distorted element is to track the value of the determinant of the deformation gradient (det $\mathbf{F}$ ) which is available directly from ABAQUS. Det $\mathbf{F}$ yields the ratio of the deformed volume, $V$, to the undeformed, $V_{0}$, volume of an element, $\operatorname{det} \mathbf{F}=V / V_{0}$. The overall element distortion criterion was subsequently based on both the fibre-dominated longitudinal damage parameter, $d_{11}^{T(C)}$, and limits on det $\mathbf{F}$ for tracking large changes in element volume,

$$
\text { Delete element if }\left\{\begin{array}{c}
d_{11}^{T(C)}>0.99 \\
0<\operatorname{det} \mathbf{F}<0.8 \text { or } \operatorname{det} \mathbf{F}>1.2
\end{array}\right.
$$

The limits on $\operatorname{det} \mathbf{F}$ are user defined and the quoted values were found to yield reliable results.

\section{2 Experimental and numerical results}

\subsubsection{Load response}

At the beginning of the crushing process (stage 1), damage was primarily in the form of local fragmentation as the trigger region was consumed. The reaction force increased gradually to the peak load at which point the entire uniform cross-section of the crush element came in contact with the platen (displacement, $\mathrm{S}=2.4 \mathrm{~mm} \sim 2.7 \mathrm{~mm}$ for the three specimen types). In the second stage, delamination initiated with a splaying mode accompanied by extensive fibre tensile and compressive fracture in the high-curvature area (highlighted in stage 2 of Figure 12), leading to a sudden drop in the reaction force as the chamfer is consumed. From stage 3 to stage 6 , outer plies deforms by bending (refers to the region to the left of the specimen edge, in Figure 12) and the inner plies tend to undergo crushing (refers to the region to the right of the specimen edge, in Figure 12). Internal debris was also created and acted like a 'wedge' in driving delamination. 
The numerical results achieved excellent quantitative correlation with experimental data without the need of calibrating any of the carefully obtained input data. The initial stiffness, peak force $\left(F_{P}\right)$ and steady-state force $\left(F_{S S}\right)$ were predicted by the numerical model with good accuracy. The sudden load drop after the peak force is attributed to fibre fracture (element deletion in the numerical simulation) and extensive delamination after the chamfer trigger was fully consumed. The progressive nature of the crushing was well captured, with a clear plateau during the steady state crushing. The overall numerical oscillations are the result of element deletion laws invoked as part of the solution and artefacts of the explicit dynamic simulation.

\subsubsection{Crushing morphology}

The numerical results from Figure 12 and Figure 13 showing the crushing morphology confirm the qualitative accuracy of the present damage model. Matrix cracking, shear fracture, delamination, lamina bending and fragmentation were well predicted. The virtual formation of fronds around the circumference shows excellent qualitative similarity when compared with experimental results both in front view and top view.

\subsubsection{Energy dissipating mechanisms}

The evolution of energy dissipated through various mechanisms during crushing is illustrated in Figure $12 b$ for all the corrugated structures tested, verifying the energy balance relationship between external work done and energy absorbed. The predicted total energy dissipated was in good agreement with the experimental total absorbed energy. The majority of energy was dissipated through intralaminar damage combining fibre tensile/compressive damage and matrix tension/compression/shear damage, followed by the friction between the crushing platen and specimen and internal friction between the plies. Extensive delamination (green line) also contributed to energy dissipation. The small amount of viscous energy dissipated is due to the use of the bulk viscosity method to damp out spurious oscillations in explicit dynamic simulations. 


\section{Conclusions}

A series of tests were conducted for the material toughness characterisation and non-linear shear behaviour of AS4/PEKK composite laminates. A DCB configuration was used to determine mode I fracture toughness while a 4ENF test was used to determine mode II fracture toughness. MMB tests were conducted to characterise the behaviour of the material under mixed-mode loading. $\mathrm{CT}$ and $\mathrm{CC}$ tests were implemented to measure the longitudinal tensile and compressive fracture toughness. V-notched shear rail tests were employed to measure the non-linear shear behaviour and fracture toughness associated with shear loading. Finite element-based verification studies, of the specimen tests themselves, were undertaken to confirm the workings of the damage model and the implementation of the material characterisation data generated from a series of tests presented in this paper. These values were further employed to predict the crushing behaviour of corrugated-shape composite specimens. Excellent qualitative and quantitative correlation was achieved between the numerical models and experimental results. The computational models were able to provide detailed information on the evolution and propagation of splaying and fragmentation of the crushing composite, involving a complex interplay of fibre fracture, matrix cracking and delamination.

\section{Acknowledgement}

The corresponding author would like to acknowledge the financial support of Bombardier and the Royal Academy of Engineering. The authors would also like to gratefully acknowledge the funding from the Queen's University Belfast/China Scholarship Council (QUB/CSC) PhD Scholarship and the support from the Research Computing Team at QUB in accessing the HPC facilities. The authors would also like to acknowledge Dr Damian Quinn for his assistance with the DIC system. 


\section{References}

[1] Vodicka R. Thermoplastics for Airframe Applications-A Review of the Properties and Repair Methods for Thermoplastic Composites. DSTO Aeronautical and Maritime Research Laboratory. 2006.

[2] ASTM. Standard Test Method for Mode I Interlaminar Fracture Toughness of Unidirectional Fiber-Reinforced Polymer Matrix Composites. D5528-13, West Conshohocken, PA 2013.

[3] Pereira AB, de Morais AB. Mixed mode I + II interlaminar fracture of glass/epoxy multidirectional laminates - Part 2: Experiments. Composites Science and Technology. 2006;66(13):1896-1902.

[4] Offringa A, List J, Teunissen J, Wiersma H. Fiber reinforced thermoplastic butt joint development. Proceedings of International SAMPE Symposium and Exhibition, 2008. [5] ASTM. Mixed Mode I-Mode II Interlaminar Fracture Toughness of Unidirectional Fibre Reinforced Polymer Matrix Composites. D6671/D6671M-13e1, West Conshohocken, PA2013.

[6] Yoshihara H. Initiation and propagation fracture toughness of solid wood under the mixed Mode I/II condition examined by mixed-mode bending test. Engineering Fracture Mechanics. 2013;104:1-15.

[7] Pinho ST, Robinson P, Iannucci L. Fracture toughness of the tensile and compressive fibre failure modes in laminated composites. Compos Sci Technol. 2006;66(13):2069-2079.

[8] ASTM. Standard test method for plane strain fracture toughness of metallic materials. E399-90, Philadelphia, PA1993.

[9] ASTM. Standard Test Method for Measurement of Fracture Toughness. ASTM E1820-15, West Conshohocken, PA2015.

[10] Jose S, Ramesh Kumar R, Jana M, Venkateswara Rao G. Intralaminar fracture toughness of a cross-ply laminate and its constituent sub-laminates. Composites Science and Technology. 2001;61(8):1115-1122.

[11] Van Paepegem W, De Baere I, Degrieck J. Modelling the nonlinear shear stressstrain response of glass fibre-reinforced composites. Part I: Experimental results. Composites Science and Technology. 2006;66(10):1455-1464.

[12] Totry E, Molina-Aldareguía JM, González C, Llorca J. Effect of fiber, matrix and interface properties on the in-plane shear deformation of carbon-fiber reinforced composites. Compos Sci Technol 2010;70(6):970-980.

[13] Feo L, Marra G, Mosallam AS. Stress analysis of multi-bolted joints for FRP pultruded composite structures. Composite Structures. 2012;94(12):3769-3780.

[14] van der Meer FP, Oliver C, Sluys LJ. Computational analysis of progressive failure in a notched laminate including shear nonlinearity and fiber failure. Composites Science and Technology. 2010;70(4):692-700.

[15] Tan W, Falzon BG, Chiu LNS, Price M. Predicting low velocity impact damage and Compression-After-Impact (CAI) behaviour of composite laminates. Composites Part A: Applied Science and Manufacturing. 2015;71:212-226.

[16] Fanteria D, Longo G, Panettieri E. A non-linear shear damage model to reproduce permanent indentation caused by impacts in composite laminates. Compos Struct 2014;111:111-121.

[17] ASTM. Standard Test Method for Shear Properties of Composite Materials by VNotched Rail Shear Method. D7078/D7078M-12, West Conshohocken, PA2012. [18] ASTM. Standard test method for shear properties of composite materials by the Vnotched beam method. D5379/D5379M-12, West Conshohocken, PA2012. 
[19] ASTM. Standard Test Method for In-Plane Shear Properties of Polymer Matrix Composite Materials by the Rail Shear Method. D4255/D4255M-15a, West Conshohocken, PA2015.

[20] Tan W, Falzon BG. Modelling the nonlinear behaviour and fracture process of AS4/PEKK thermoplastic composite under shear loading. Compos Sci Technol 2016;126:60-77.

[21] Tan W, Falzon BG, Price M. Predicting the crushing behaviour of composite material using high-fidelity finite element modelling. International Journal of Crashworthiness. 2015;20(1):60-77.

[22] Chiu LNS, Falzon BG, Boman R, Chen B, Yan W. Finite element modelling of composite structures under crushing load. Composite Structures. 2015;131:215-228. [23] Faggiani A, Falzon BG. Predicting low-velocity impact damage on a stiffened composite panel. Composites Part A: Applied Science and Manufacturing. 2010;41(6):737-749.

[24] Camanho PP, Davila CG. Mixed-mode decohesion finite elements for the simulation of delamination in composite materials. NASA-Technical Paper. 2002;211737(1):33.

[25] Falzon BG, Apruzzese P. Numerical analysis of intralaminar failure mechanisms in composite structures. Part II: Applications. Compos Struct. 2011;93(2):1047-1053.

[26] Falzon BG, Apruzzese P. Numerical analysis of intralaminar failure mechanisms in composite structures. Part I: FE implementation. Compos Struct. 2011;93(2):10391046.

[27] Tan W, Falzon BG. Modelling the crush behaviour of thermoplastic composites. 2015; Submitted.

[28] Cytec. APC-2 PEKK Thermoplastic Polymer Technical Data Sheet. Cytec Engineering Materials. 2012.

[29] Puck A, Schürmann H. Failure analysis of FRP laminates by means of physically based phenomenological models. Compos Sci Technol. 1998;58(7):1045-1067.

[30] Catalanotti G, Camanho PP, Marques AT. Three-dimensional failure criteria for fiber-reinforced laminates. Composite Structures. 2013;95:63-79.

[31] Press WH. Numerical recipes in Fortran 77: the art of scientific computing: Cambridge university press; 1992.

[32] Fleming DC. Modelling composite crushing initiation using a cohesive element formulation. Int J Crash. 2011;16(5):475-485.

[33] Benzeggagh M, Kenane M. Measurement of mixed-mode delamination fracture toughness of unidirectional glass/epoxy composites with mixed-mode bending apparatus. Composites Science and Technology. 1996;56(4):439-449.

[34] Schuecker C, Davidson BD. Evaluation of the accuracy of the four-point bend endnotched flexure test for mode II delamination toughness determination. Composites Science and Technology. 2000;60(11):2137-2146.

[35] de Morais AB, de Moura MFSF. Evaluation of initiation criteria used in interlaminar fracture tests. Engineering Fracture Mechanics. 2006;73(16):2264-2276. [36] Simulia. Abaqus 6.12 documentation. Providence, Rhode Island, US. 2012. [37] Laffan MJ, Pinho ST, Robinson P, McMillan AJ. Translaminar fracture toughness testing of composites: A review. Polymer Testing. 2012;31(3):481-489.

[38] Czabaj MW, Ratcliffe J. Comparison of Intralaminar and Interlaminar Mode-I Fracture Toughness of Unidirectional IM7/8552 Graphite/Epoxy Composite. 2012. [39] Pinho S, Iannucci L, Robinson P. Physically-based failure models and criteria for laminated fibre-reinforced composites with emphasis on fibre kinking: Part I: 
Development. Composites Part A: Applied Science and Manufacturing. 2006;37(1):6373.

[40] Vyas GM, Pinho ST. Computational implementation of a novel constitutive model for multidirectional composites. Computational Materials Science. 2012;51(1):217-224. [41] Preetamkumar M, Gilles L, Pierre L, Ana-cristina G. Validation of Intralaminar Behaviour of the Laminated Composites by Damage Mesomodel. 50th

AIAA/ASME/ASCE/AHS/ASC Structures, Structural Dynamics, and Materials Conference: American Institute of Aeronautics and Astronautics; 2009. 


\section{Figures}

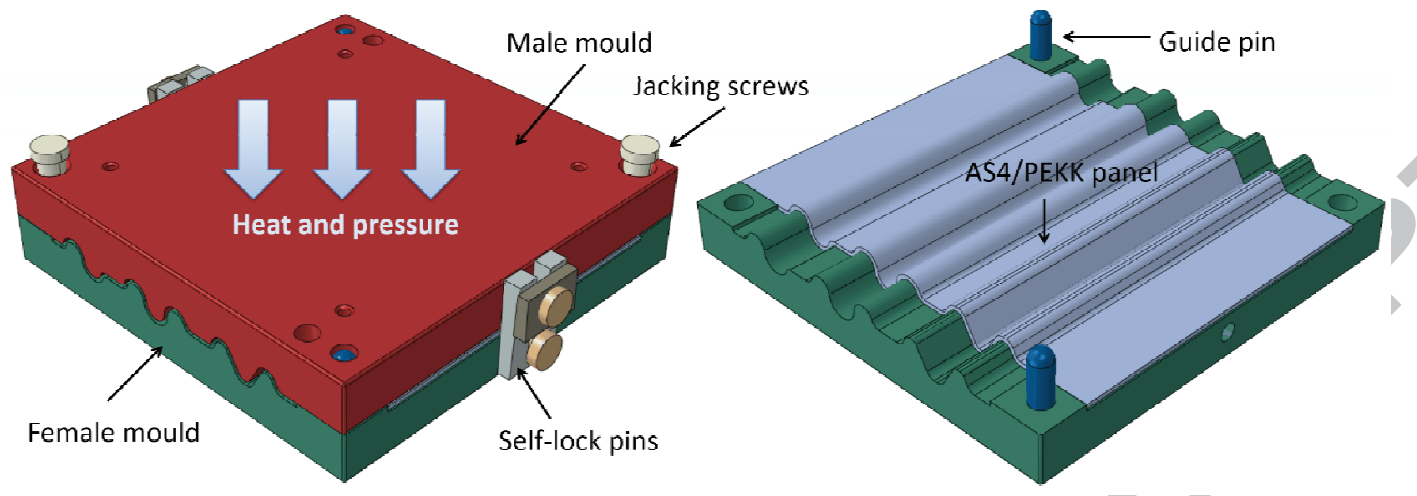

(a)

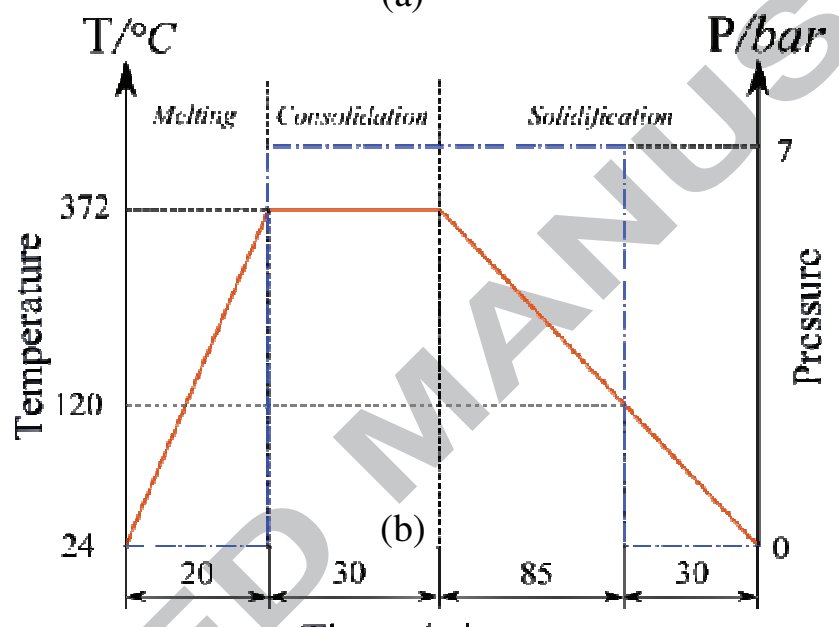

Time, t/min

Figure 1. (a) Specimen preparation process and (b) consolidation cycle for PEKK composites 


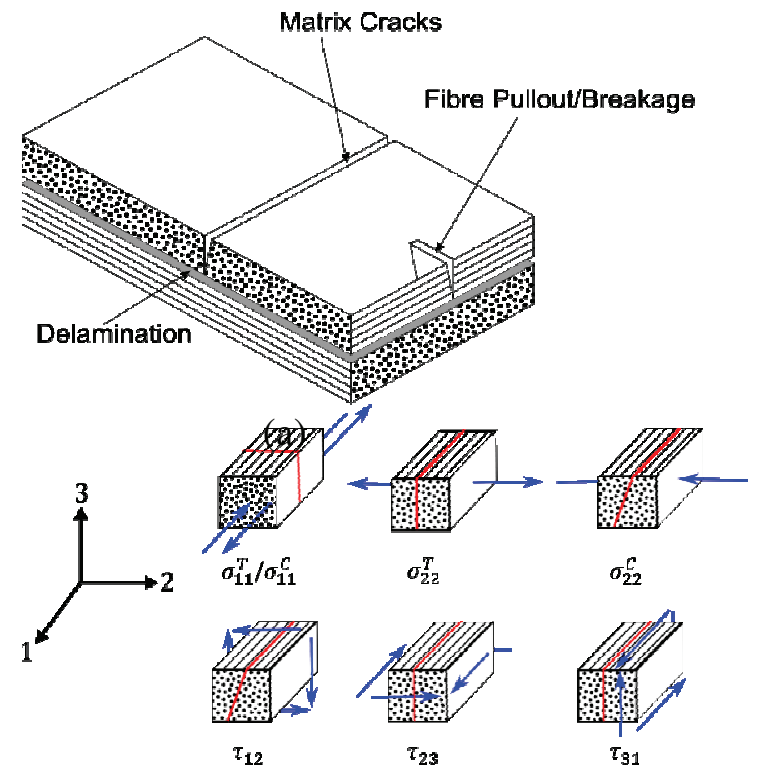

(b)

Figure 2. (a)Damage modes in laminated composites (b) damage associated with different loading conditions (fracture plane marked in red) 


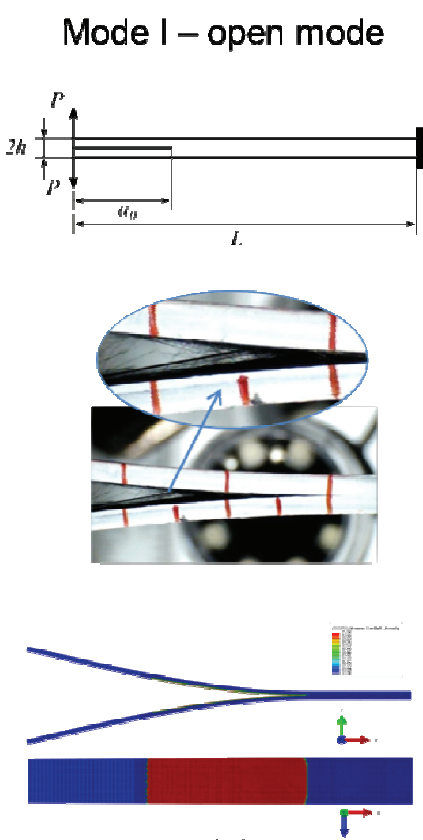

(a)
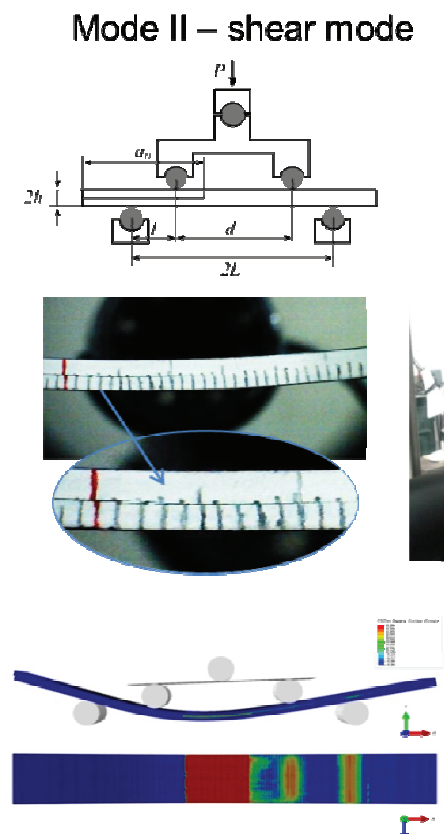

(b)
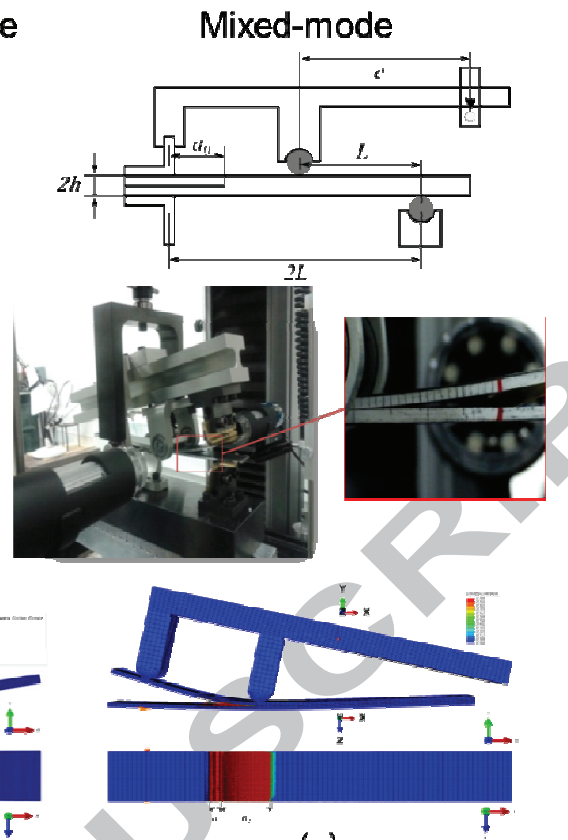

(c)

Figure 3. Interlaminar fracture toughness characterisation tests and simulation of (a) DCB (b) 4ENF and

(c) MMB tests
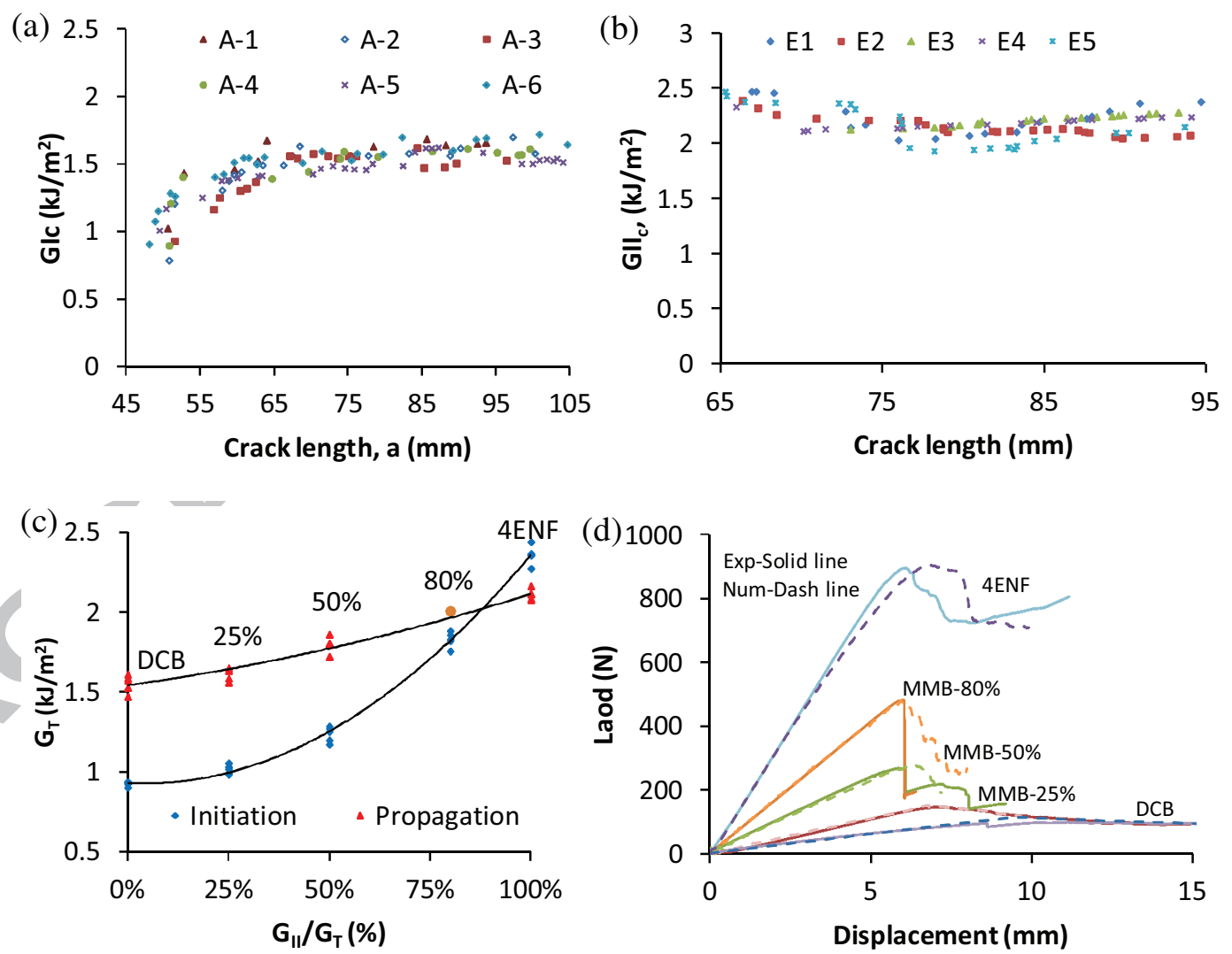

Figure 4. (a)Fracture toughness values for mode I, (b)mode II and (c)mixed-mode; (d) Experimental and numerical results 

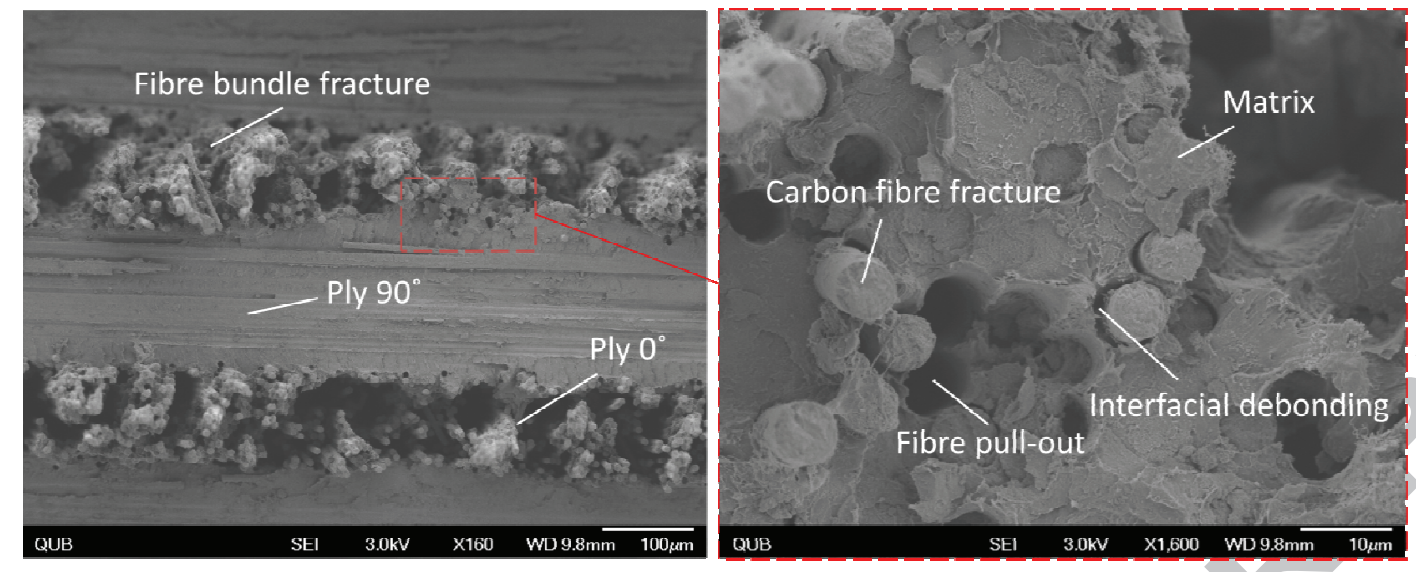

Figure 5. SEM images of CT tested specimen fracture surface

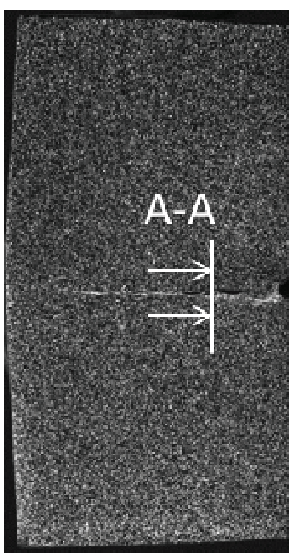

(a)

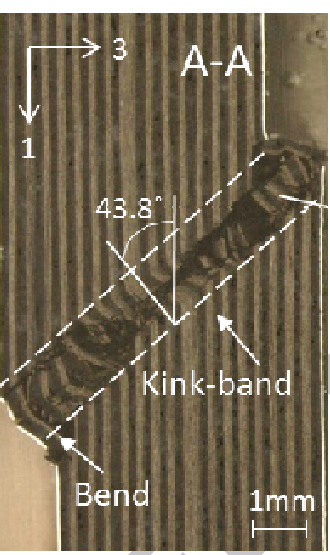

(b)

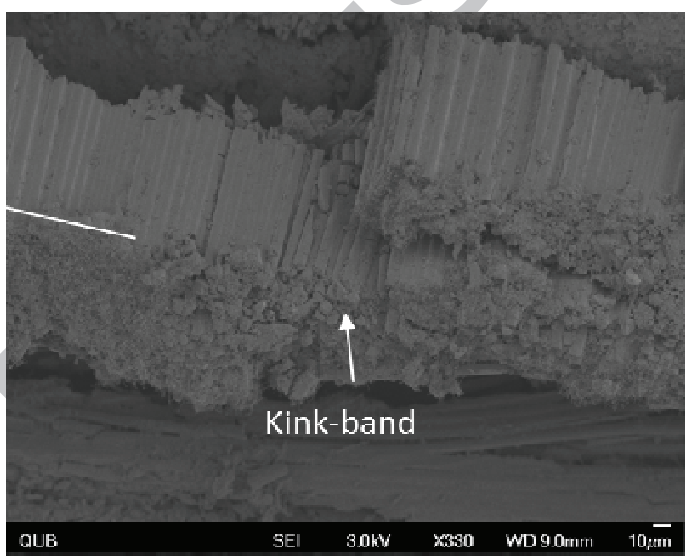

(c)

Figure 6. Experimental tests: (a) CC tested specimen (b) kinking failure under optical microscope (c) kinkband failure observed in the SEM image of a CC specimen. 


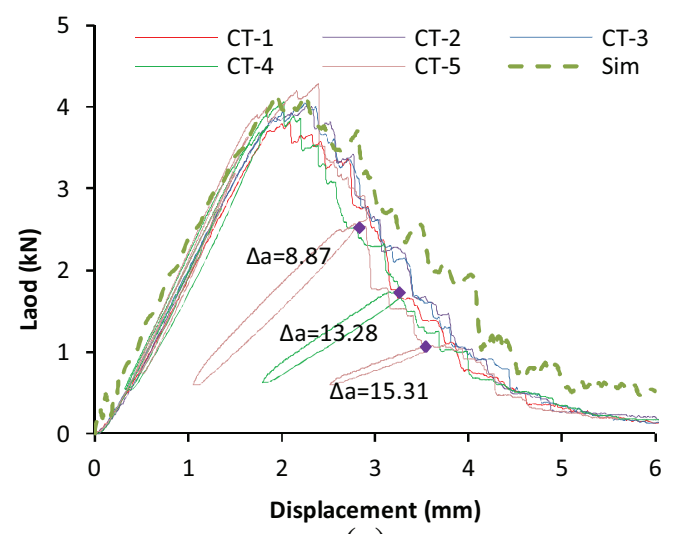

(a)

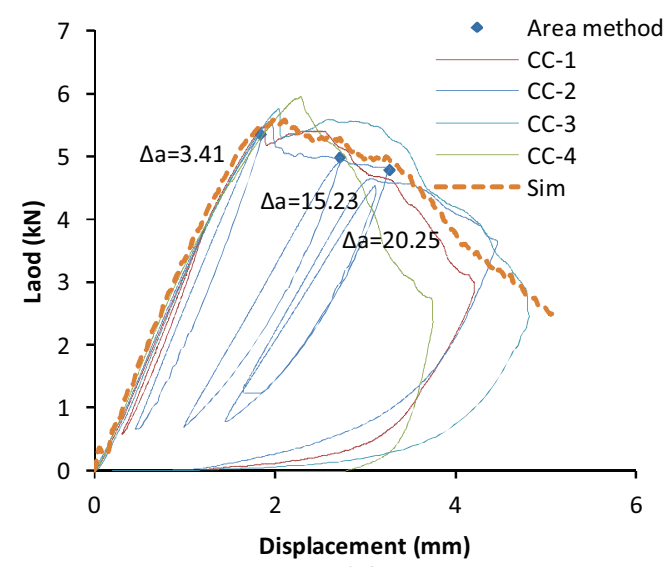

(c)

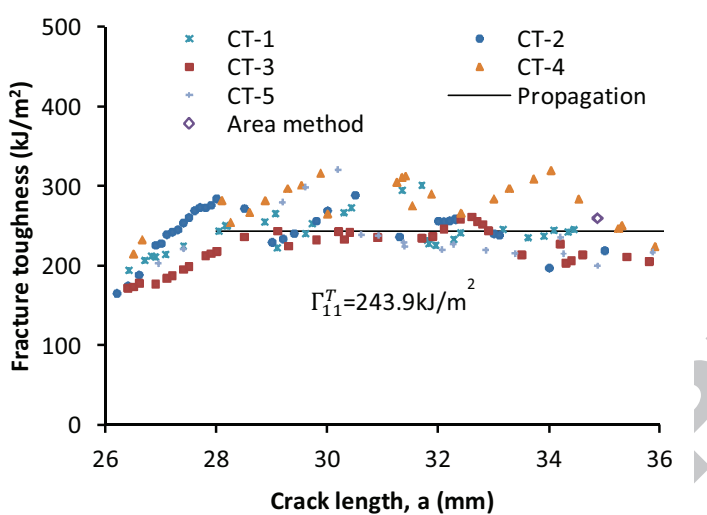

(b)

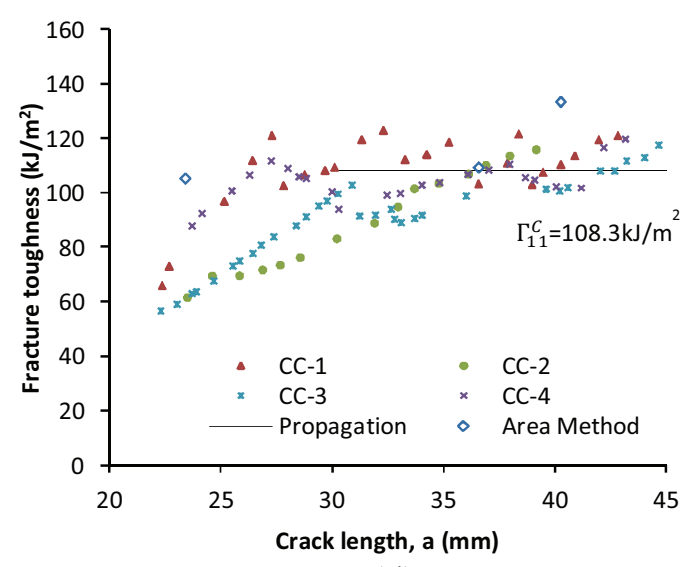

(d)

Figure 7. (a)Load-displacement curves and (b) R-curves of CT tests; (c) Load-displacement curves and (d) $R$-curves of CC tests; 


\section{Compact Tension}

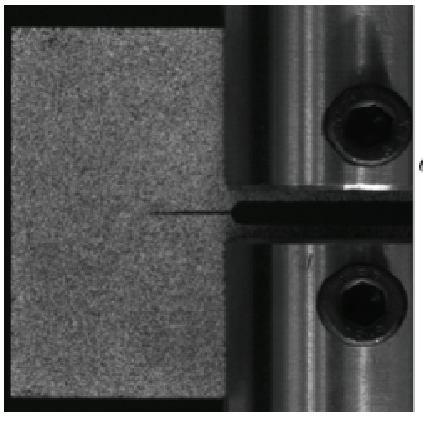

Setup

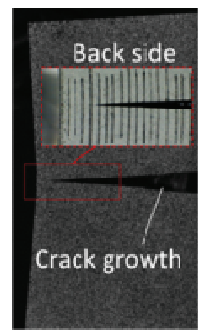

Exp

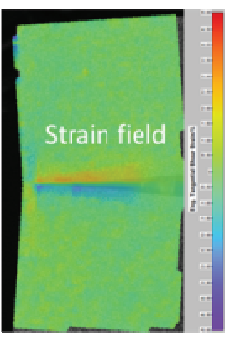

Exp-D $\mid \mathrm{C}$

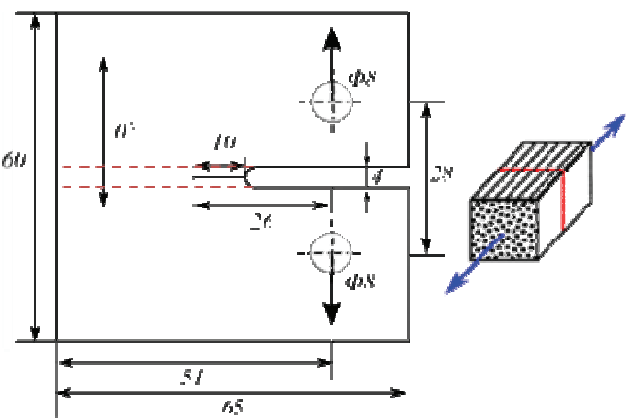

Dimensions

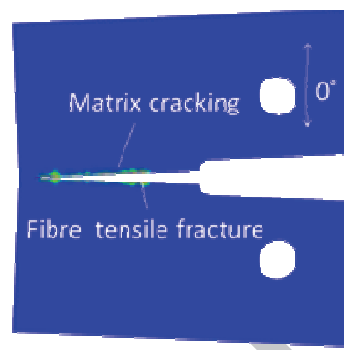

Num

(a)

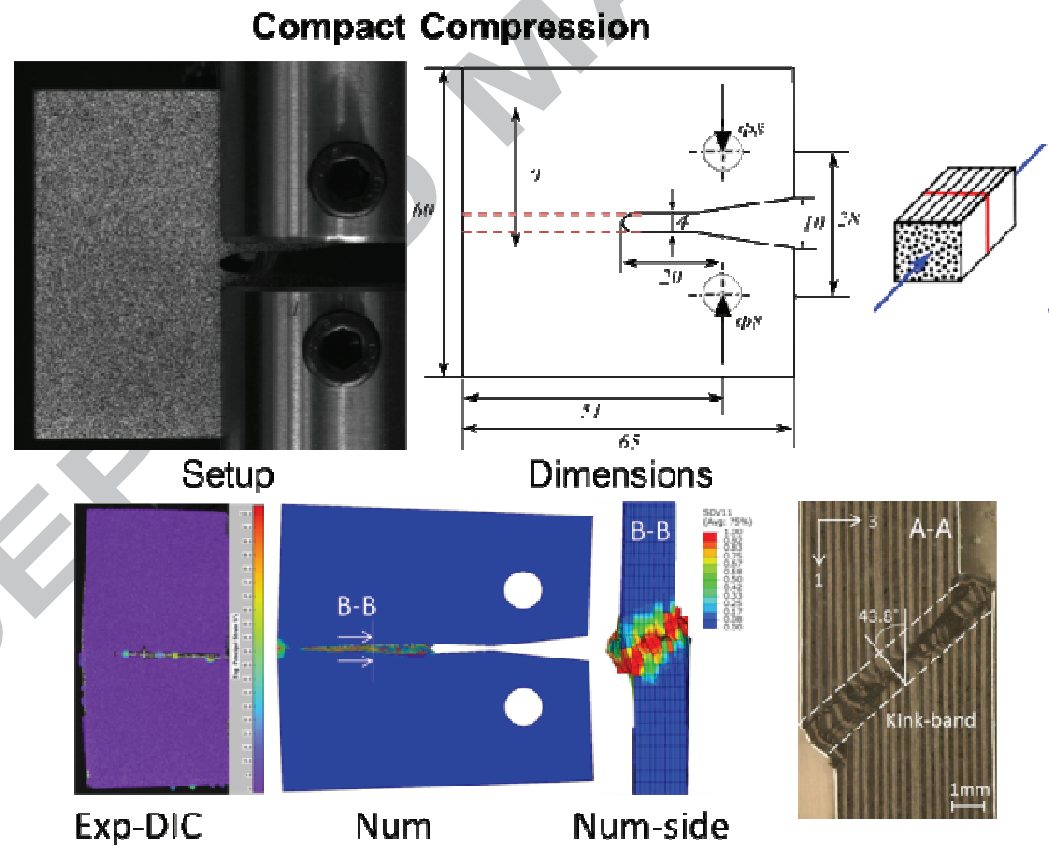

(b)

Figure 8. Experimental and numerical results of (a) CT and (b) CC tests 


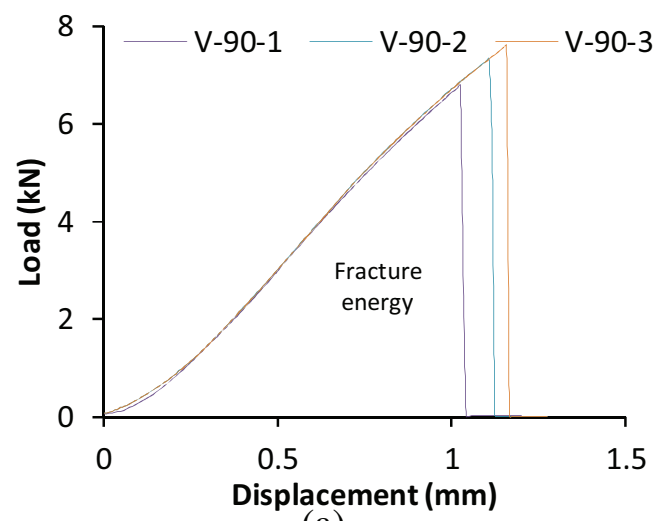

(a)

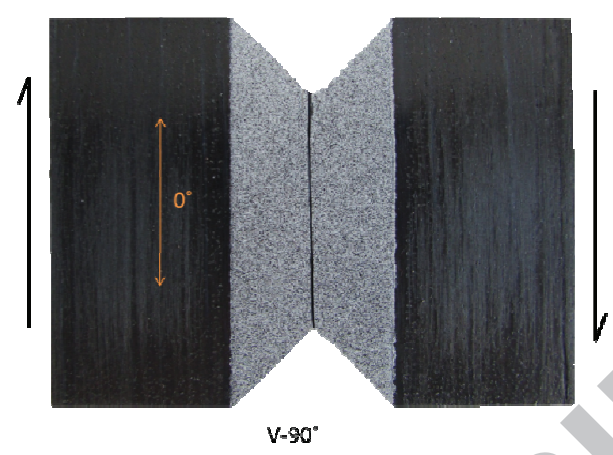

(b)

Figure 9. (a) Load-displacement curves and (b) tested unidirectional specimens.

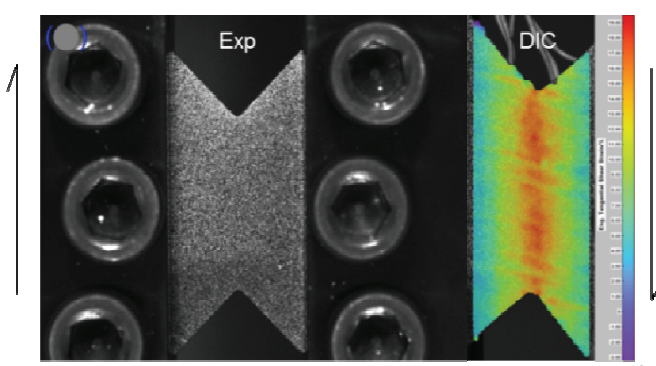

(a) Test setup

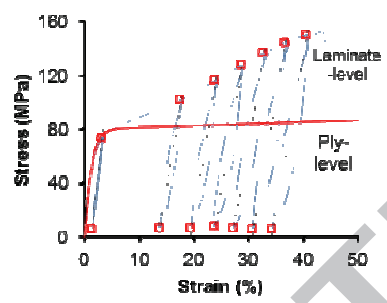

(c) Stress-strain

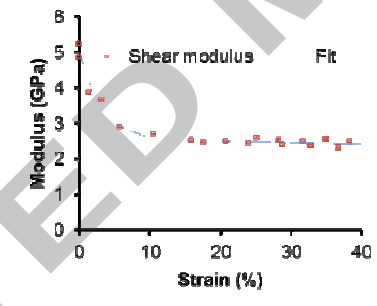

(d) Modulus-strain

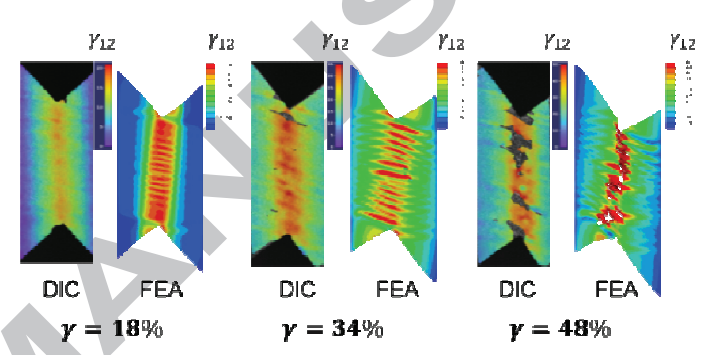

(b) Strain-field

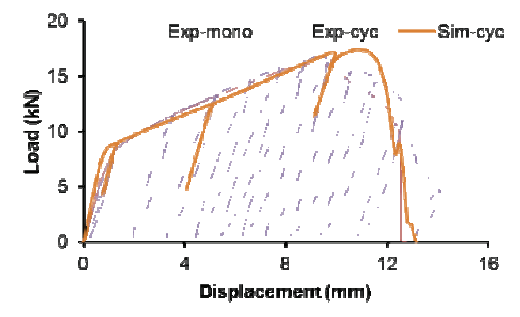

(e) Load-displacement

Figure 10: (a) Test setup (b) Strain field from DIC and FEA(c) Stress-strain curves (d) Modulus-strain curve (e) Load-displacement curve 


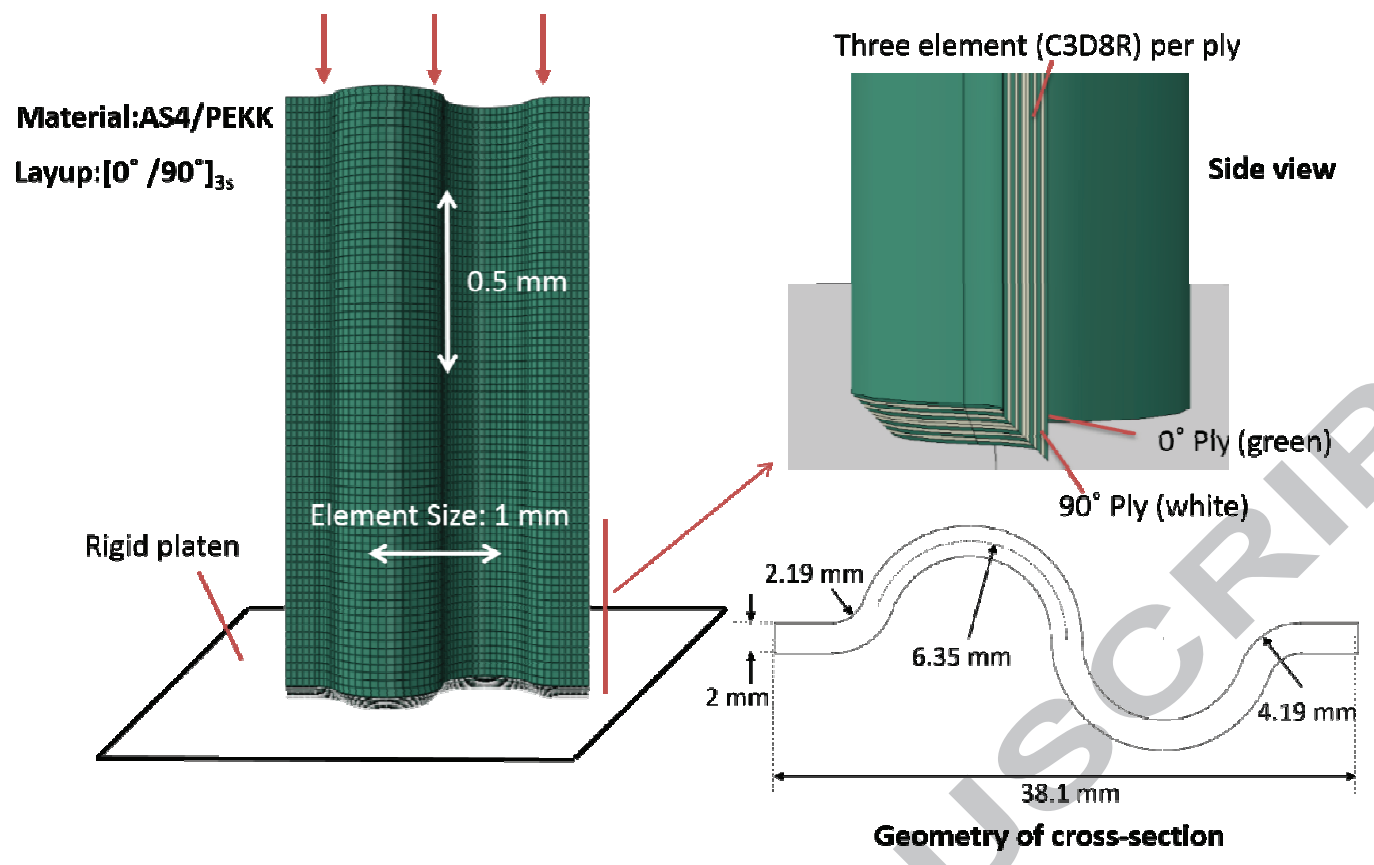

Figure 11. Geometry and finite element model of self-supporting corrugated composite specimen 


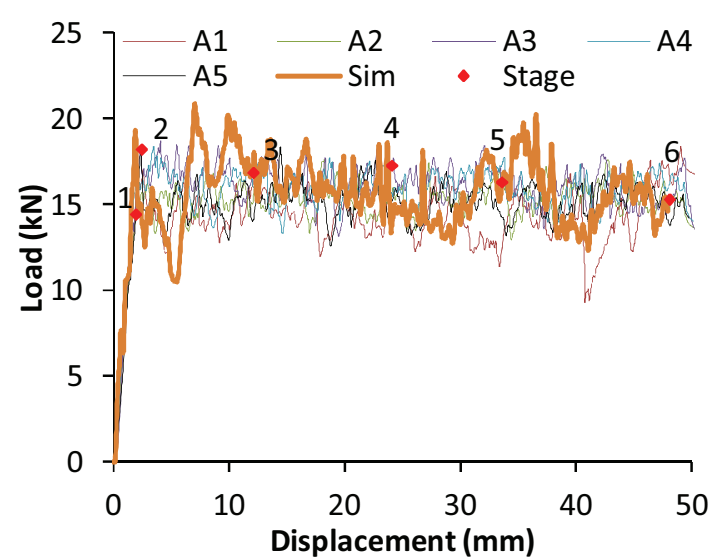

(a)
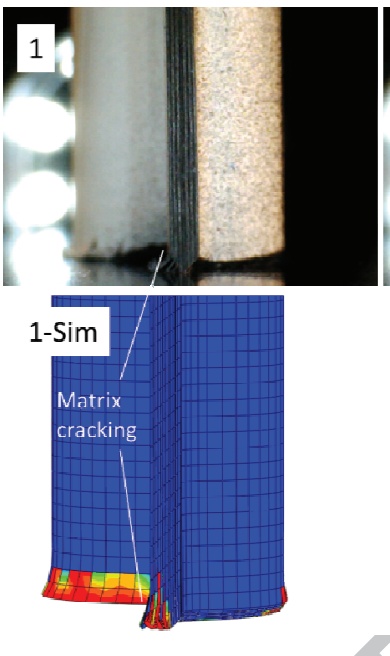
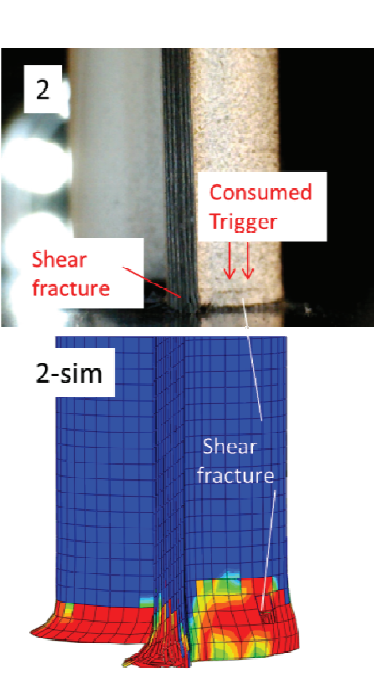

(c)

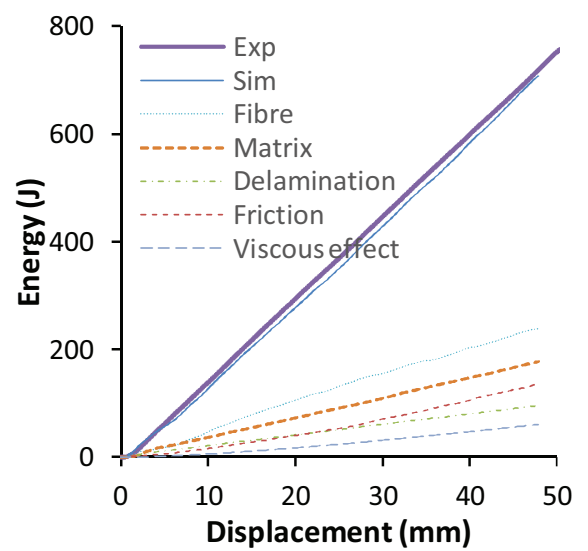

(b)

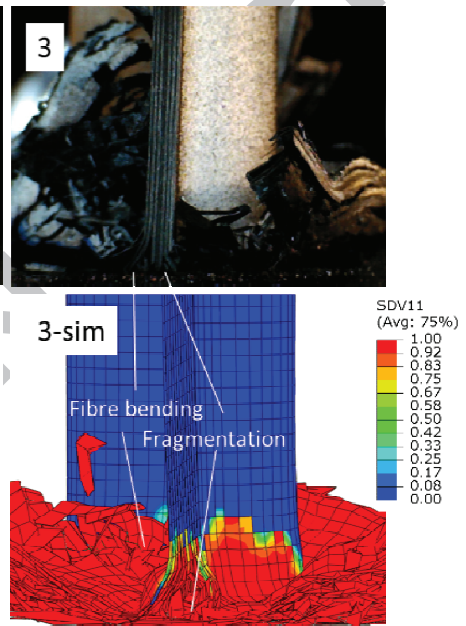

Figure 12. Corrugated specimens:(a) Load-displacement curves; (b) Energy dissipation mechanisms; (c) Side view of failure process 

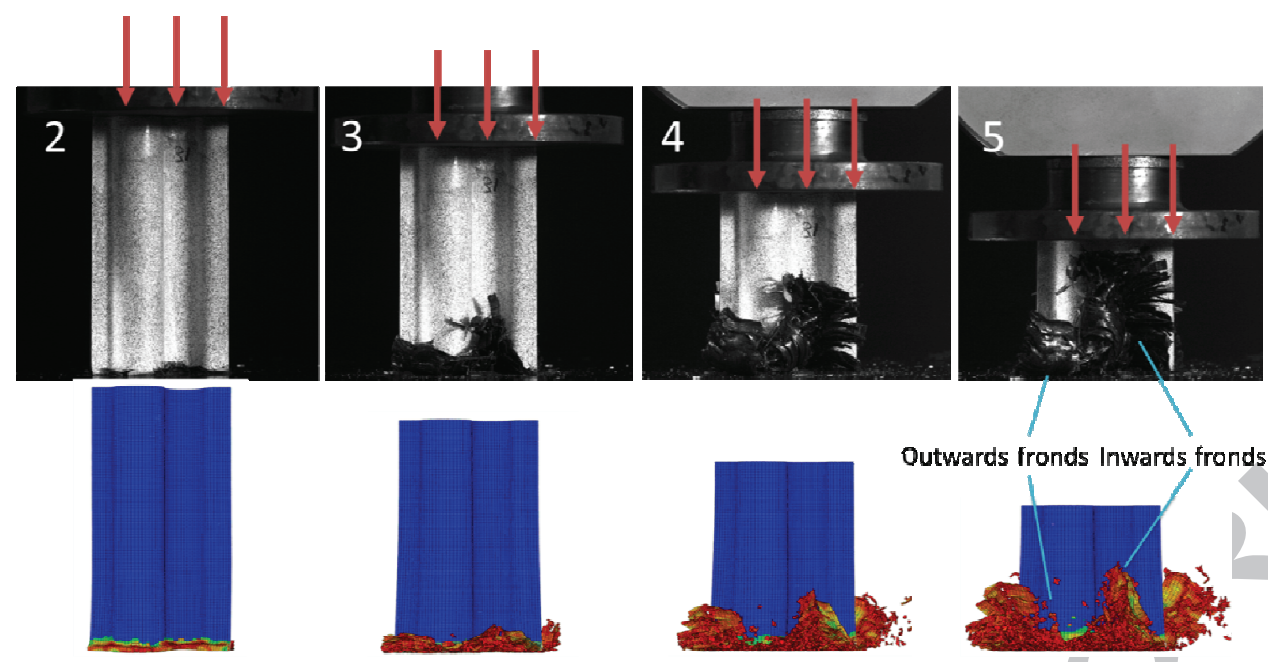

Outwards fronds Inwards fronds

(a) Front view

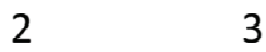

4
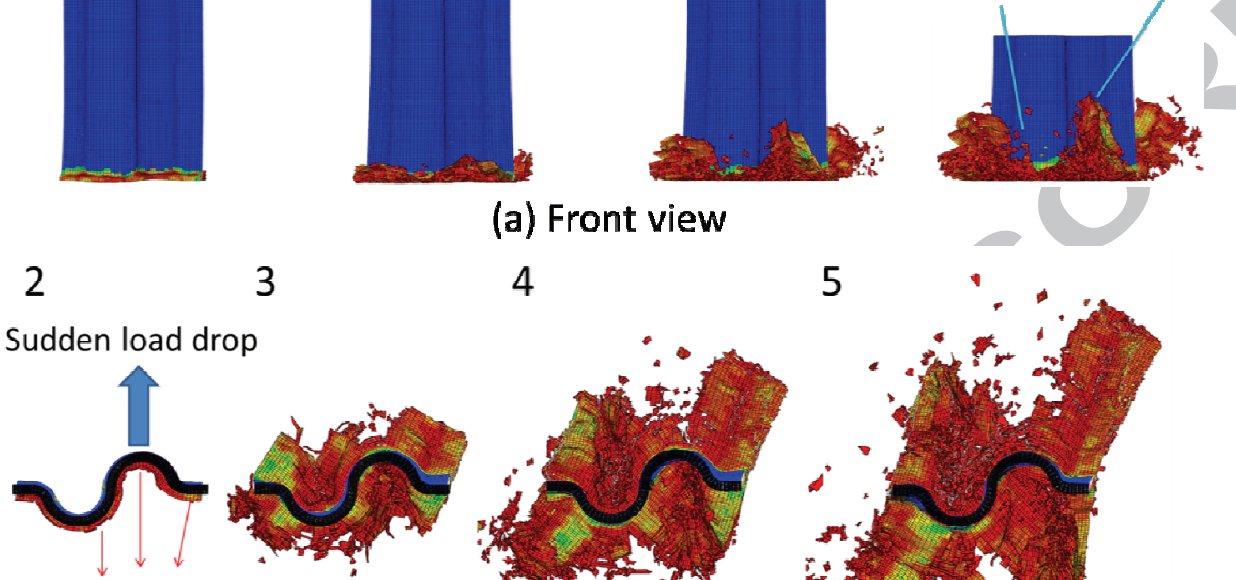

Fibre breakage

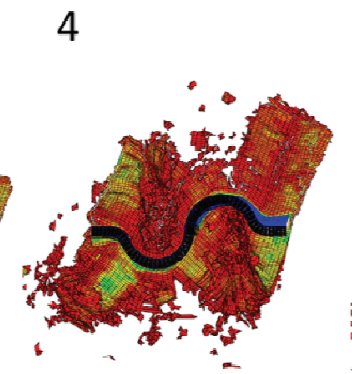

5

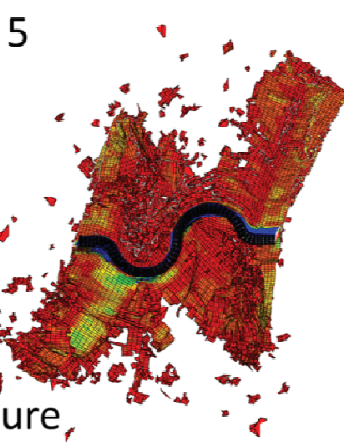

Fibre compressive failure,
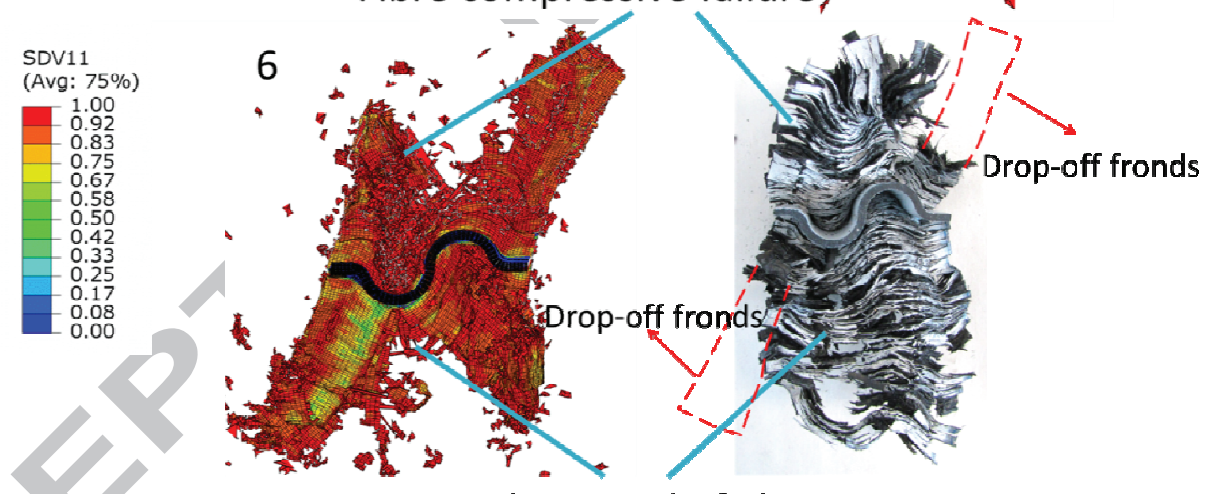

Fibre tensile failure

(b) Top view

Figure 13. Corrugated specimens: Experimental and numerical matrix damage results (a) front and (b) top view 


\section{Tables}

Table 1. Dimensions of tested specimens and configurations (dimension, $\mathrm{mm}$ )

\begin{tabular}{cccccc}
\hline Tests & Length $\boldsymbol{l}$ & Outer span $2 \boldsymbol{L}$ & Inner span $\boldsymbol{d}$ & Precrack length $\boldsymbol{a}_{\mathbf{0}}$ & Loading rate \\
\hline DCB & 150 & - & - & 50 & $2 \mathrm{~mm} / \mathrm{min}$ \\
4ENF & 180 & 140 & 70 & 70 & $1 \mathrm{~mm} / \mathrm{min}$ \\
MMB & 160 & 100 & 50 & 25 & $0.5 \mathrm{~mm} / \mathrm{min}$ \\
\hline
\end{tabular}

Table 2. Material properties for the composite damage model

\begin{tabular}{ll}
\hline \multicolumn{1}{c}{ Property } & \multicolumn{1}{c}{ Values } \\
\hline \multirow{2}{*}{ Elastic Properties [28] } & $\mathrm{E}_{1}=139 \mathrm{GPa} ; \mathrm{E}_{2}=\mathrm{E}_{3}=10.3 \mathrm{GPa} ; \mathrm{G}_{23}=3.96 \mathrm{GPa} ;$ \\
& $\mathrm{G}_{12}=\mathrm{G}_{13}=5.2 \mathrm{GPa} ; \mathrm{v}_{12}=\mathrm{v}_{13}=0.3 ;$ \\
\hline \multirow{2}{*}{ Strength [28] } & $X_{T}=2463 \mathrm{MPa} ; \mathrm{X}_{\mathrm{C}}=1493 \mathrm{MPa} ; Y_{T}=102 \mathrm{MPa} ;$ \\
& $Y_{C}=254 \mathrm{MPa} ; \mathrm{S}_{12}=\mathrm{S}_{13}=80.81 \mathrm{MPa}$ \\
\hline \multirow{3}{*}{ Intralaminar Fracture Toughness } & $\Gamma_{11}^{\mathrm{T}}=243.9 \mathrm{~kJ} / \mathrm{m}^{2} ; \Gamma_{11}^{\mathrm{C}}=108.3 \mathrm{~kJ} / \mathrm{m}^{2} ; \Gamma_{22}^{\mathrm{T}}=$ \\
& $1.564 \mathrm{~kJ} / \mathrm{m}^{2} ; \Gamma_{22}^{\mathrm{C}}=34.58 \mathrm{~kJ} / \mathrm{m}^{2} ; \Gamma_{12}=\Gamma_{23}=\Gamma_{13}=$ \\
\hline \multirow{2}{*}{ Non-linear Shear Properties } & $34.58 \mathrm{~kJ} / \mathrm{m}^{2} ;$ \\
\hline \multirow{3}{*}{ Interface Properties } & $\tau_{i j}^{Y}=80.81 ; \alpha=0.16 ; \beta=-44.26$ \\
& $\mathrm{p}_{1}=2405 ; \mathrm{p}_{2}=-32.59 ; \mathrm{p}_{3}=2596 ; \mathrm{p}_{4}=-0.1764$ \\
\hline & $G_{I C}=1.5649 \mathrm{~kJ} / \mathrm{m}^{2} ; G_{I I C}=2.1139 \mathrm{~kJ} / \mathrm{m}^{2} ; \eta=$ \\
& $0.996 ; \tau_{3}^{0}=61 \mathrm{MPa} ; \tau_{1(2)}^{0}=68.4 \mathrm{MPa} ; \mathrm{k}=1 \times$ \\
& $10^{5} \mathrm{~N} / \mathrm{mm}^{3}$ \\
\hline
\end{tabular}

